NBSIR 75-911

\title{
A National Network Data Base System
}

Richard H. F. Jackson

Applied Mathematics Division Institute for Basic Standards

Washington, D. C. 20234

September 1975

Technical Report to:

Office of the Secretary

U.S. Department of Transportation

Bureau of Economic Analysis U.S. Department of Commerce

Office of the Chief of Engineers

U.S. Department of the Army

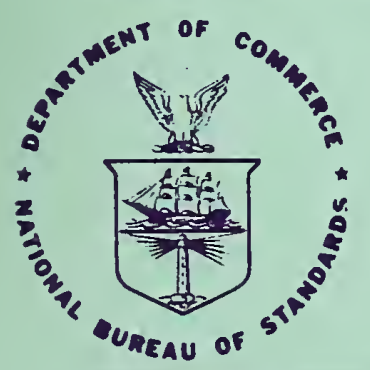

U S. DEPARTMENT OF COMMERCE

NATIONAL BUREAU OF STANDARDS 



\section{A NATIONAL NETWORK DATA BASE SYSTEM}

Richard H. F. Jackson

Applied Mathematics Division Institute for Basic Standards

Washington, D. C. 20234

September 1975

Technical Report to:

Office of the Secretary

U.S. Department of Transportation

Bureau of Economic Analysis

U.S. Department of Commerce

Office of the Chief of Engineers

U.S. Department of the Army

U.S. DEPARTMENT OF COMMERCE, Rogers C. B. Morton, Secretary James A. Baker, III, Under Secretary

Dr. Betsy Ancker-Johnson, Assistant Secretary for Science and Technology

NATIONAL BUREAU OF STANDARDS, Ernest Ambler, Acting Director 



\section{ABSTRACT}

This report documents a data base "system" created at the National Bureau of Standards. The NationaI Network Data Base System (NNDBS) provides information on intercity flows of freight and passengers throughout the United States. It consists of a set of FORTRAN programs written for the NBS computer (but transportable) and some basic data tapes. In addition to providing basic data on the modal transportation networks, and interregional flows of passengers and freight, the NNDBS can make estimates of market splits among modes, can perform aggregations over certain "zones" in the U.S., and is capable of easy extension to other uses. This report is intended as a user's guide and includes discussions of the data tapes and each of the programs. Complete 1istings and tape formats are also included.

Keywords: Commodity flows, data base, freight mode choice, market split, modal choice, modal freight flows, national transport analyses, regional transport analysis, transportation network 


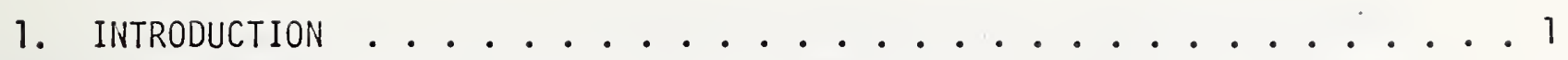

2. THE BASIC DATA TAPES--NETTO, NET8O, AND NET9O ............ 4

3. THE MODAL SPLIT PROGRAMS--SPLIT . . . . . . . . . . . . . 6

4. THE STATE AGGREGATIOH PROGRAMS--STAG . . . . . . . . . . 10

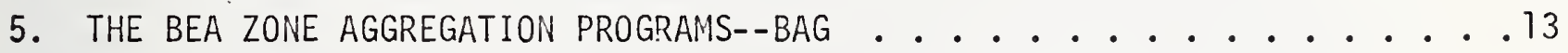

6. CONCLUSION . . . . . . . . . . . . . . . . . . . . . . . . . . . . . . . . .

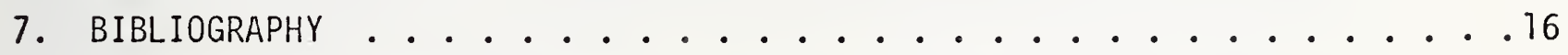

8. APPENDIX A: COMPUTER FORIMAT OF NET70, NET80, AND NET9O . . . . . . 17

9. APPENDIX B: COMPUTER FORMAT OF THE PASSENGER TAPE--NETPS . . . . . 18

10. APPENDIX C: COMPUTER FORMAT OF THE ALTERNATE IMPEDANCE TAPE--NETTS . 19

11. APPEINDIX D: COMPUTER FORMAT OF THE SPLIT TAPES--SPL70, SPL80, AND SPL90 . 20

-12. APPENDIX E: COMPUTER FORMAT OF THE STAG TAPES--STG70,STG80, AND STG90. . 21

13. APPENDIX F: COMPUTER FORMAT OF THE BAG TAPES--BAG70,BAG80, AND BAG90 . .22

14. APPENDIX G: LISTING OF THE SPLIT PROGRAMS . . . . . . . . . . . 23

15. APPENDIX H: LISTING OF THE STAG PROGRAMS . . . . . . . . . 28

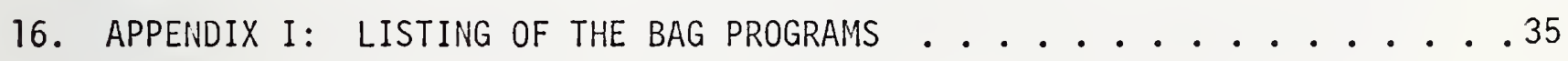

\section{LIST OF FIGURES}

FIGURE 1: THE TAPES AND PROGRAMS OF THE NATIONAL NETWORK DATA BASE SYSTEM . . 2 FIGURE 2: THE MATRIX OF POSSIBLE CONINECTIONS ............. 7

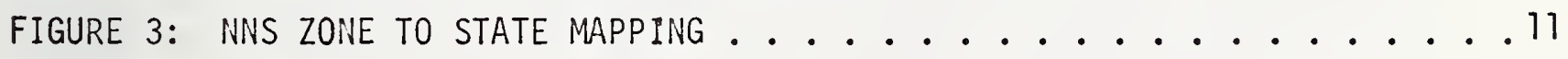



This report documents the National Network Data Base System (NivDBS) from a programmer/user point of view. The IMDBS was created at the National Bureau of Standards in order to provide information on flows of freight and passengers on the major intercity transportation network of the United States. The reasons for developing such a data base, the rationale used in producing the basic data, and the checks used to assure validity, are al1 given in [4]. The present report aims to provide documentation sufficient to permit ready use of the Data Base system by any competent programmer. It could, therefore, be viewed as a user's guide to the MNDBS.

The MDDS is properly called a "system" because some of the data available from it are not stored explicitly, but can be obtained by applying one or more of its programs to one of its basic data tapes. The alternative to such a "systematized data base" would be actual storage of all the various manifestations of the basic data tapes. This would result in at least 12 separate and nearly-full reels of magnetic tape. It was felt that the creation and use of so large a conventional data base would involve too great a risk of crippling physical tape problems such as unrecoverable parity errors which could completely destroy the usefulness of a given data base tape. Although reliability for such a conventional data base can be obtained through maintenance of complete listings and backup tapes, the required costs, not only in terms of datastorage, but also in personnel time to maintain the massive structure, appeared too high to justify such an approach. It was therefore decided to create a data base "system" in the sense described above. This approach would keep at a minimum the number of tapes stored, thus keeping at a minimum the number of backup tapes and complete listings. The programs are kept on mass storage files.

A pictorial representation of the NNDBS is given in Figure 1. From that representation, it can quickly be seen that all tapes are derivable from the single tape called NET70, so that just NET70 and a number of programs could be kept as "the system". However, it was decided to keep three tapes, NET70, NET80, and NET9O as the basic data tapes in the system for a number of reasons. These include the fact that the program FRATAR (see p. 223 of [5]), which produces NET80 and NET9O from NET70 by a technique known as Fratar projection (see [2]), was written for the IBM 360 , and that it need only be run once for eacha tape (NET80 and NET90) in question. The cost of converting FRATAR to be acceptable to the NBS UNIVAC 1108, and of updating it for use in the NNDBS was deemed higher than the extra two-tape-maintenance-costs incurred by having the three basic data tapes.

Before moving on to a discussion of the data ot the tapes and to a presentation of the programs, we note that there ara two other tape files which do not appeär in Figure 1: NETTS and NETPS. NETTS is a test tape which contains an "alternative network" to the one represented in the other data base tapes. Fore on NETTS can be found in the 



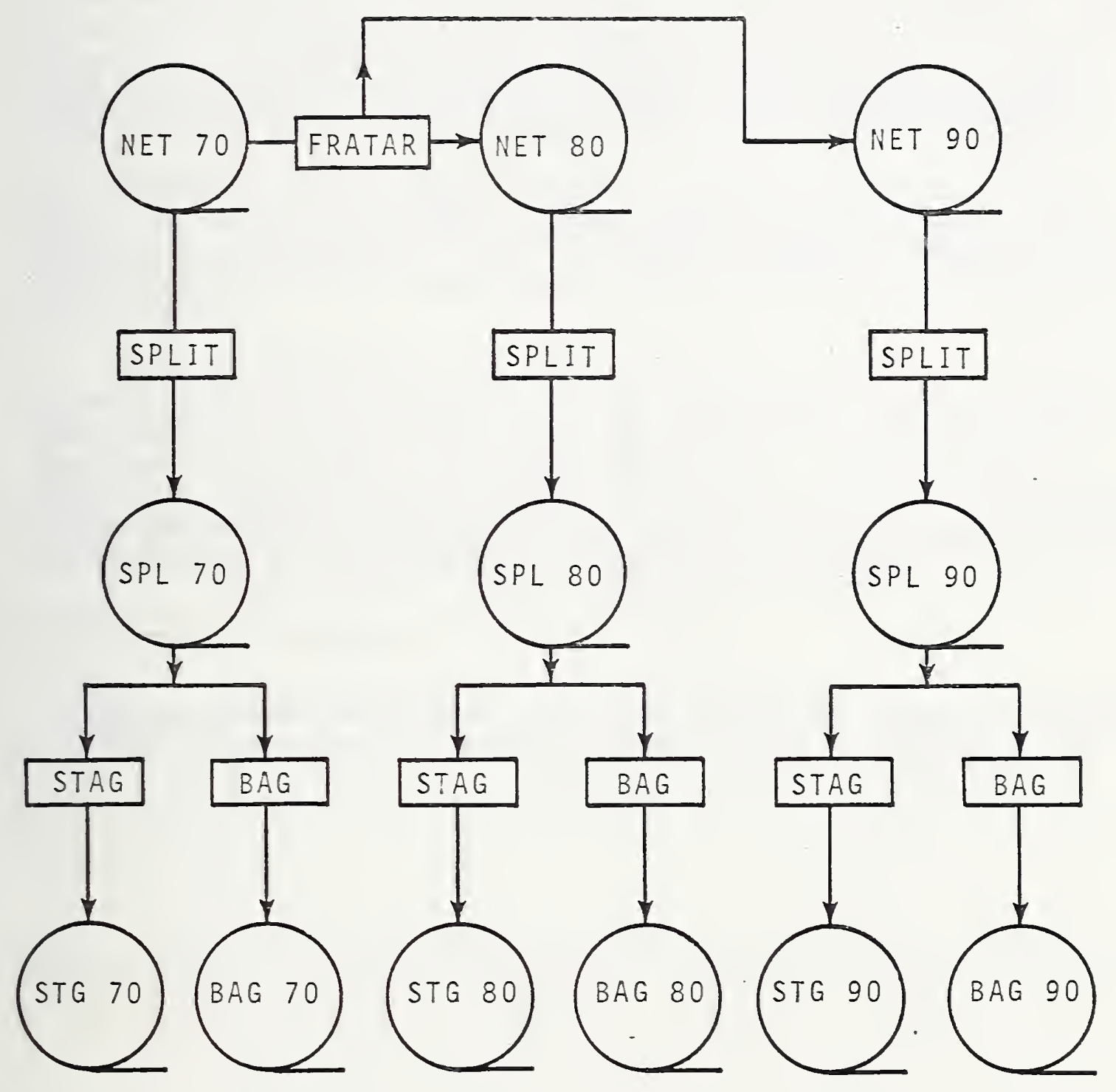

FIGURE 1: THE TAPES AND PROGRAIIS OF THE NATIONAL NETWORK DATA BASE SYSTEM 
. 
discussion of the program SPLIT, and its format is given in Appendix C. NETPS contains information on intercity passenger movements throughout the national transportation system. Nothing more than storage is currentiy planned for NETPS, so that nothing more about it will be presented in the present document except for its computer format, given in Appendix B.

The programs in the NNDBS were written in FORTRAN for the NBS UNIVAC 1108-* but none are machine dependent. Some wi11, however, require modification before being transported to another computer. The modifications required are a 11 related to block transfer of data and occur only in the driver programs discussed in Sections 3, 4, and 5. Some form of binary block transfer of data should be substituted for each reference to the utility package NTRAN found in those programs.

Section 2 of this report presents a detailed discussion of the basic data tapes in the NNDBS, while Sections 3, 4, and 5 take up the programs used to move from level to level in Figure 1. There are six Appendices giving tape formats, and three more containing listings of the programs.

To be most effective, reading of Sections $2,3,4$, and 5 should be accompanied by regular reference to the formats and listings given in the Appendices. A word here on the organization of the listings in Appendices G, H, and I, is therefore appropriate. Each of those three appendices contains three separate listings: the first is of the control stream required for a run; the second, of the driver program in the run; and the third, of the respective "workhorse" subroutine.

*A7though program development took place on the NBS computer (a UNIVAC 1108), no endorsement of UNIVAC or UNIVAC equipment is intended. 
This section discusses the basic data tapes NET70, MET80, and NET90. Since NET80 and NET90 are direct7y derivable from MET70 and their computer format is exactly the same, the discussion will center around NET70. Differences between the 1970 tape (MET70) and the 1980 and 1990 tapes (IIET80 and NET9O, respectively) are noted at the end of the section.

NET70 contains information on freight movements throughout the U. S. and its possessions for the year 1970. The information is stored as flows among certain "zones" in the U.S. These zones, called llational Network Simulation (NMS) zones, were mapped out previous to this project. (For more on iNS zones, see [3, 4].) There are 512 such wis zones, and each record on NET70 contains data on one-way freight movements between a particular pair of zones. A11 the data stored on NETTO falls into two categories: amount of goods shipped, and the impedances (distance and time) involved in shipping it.

The total flow of freight from one zone to another has been broken down into eight commodity classes, measured in tons:
1) large, high value shipments,
2) small, high value shipments,
3) large, medium value shipments,
4) sma11, medium value shipments,
5) large, low value shipments,
6) small, low value shipments,
7) large, crude oil shipments,
8) large, refined oil shipments.

Therefore, a tape record contains an entry for each of the above commodity classes, representing the average daily flow of goods;, from the origin NNS zone to the destination NNS zone, of that commodity class and size. The identification numbers of the origin and destination ivis zones also appear in the record.

The interzonal impedances are associated with the various modes of transportation. The NNDBS deals with six possible modes of shipping a commodity from one zone to another:
1) truck,
2) rail,
3) air,
4) water,
5) crude oil pipeline,
6) refined oil pipeline.

* The flow of goods is measured in tons. 


$$
\text { . }
$$


Each tape record contains an entry for each of the above six modes, which entry represents the distance in statute miles by each mode between the zone pair for that record. The record also contains time entries, namely the times (in minutes) required to traverse each of the above distances via the associated mode. Each record on NET70, therefore, contains 22 entries: the origin-destination NNS zone numbers, 6 distance entries, 6 time entries, and 8 commodity-class quantity entries.

The tape contains one record for every zonal pair that is connected and has a nonzero flow. When the data tape was first created, the iNs zones were considered to be completely connected--a link was presumed to exist between each possible pairing. However, it was soon discovered that many such links had zero flow for all commodity classes. A culling process was then performed to remove these "zero" records from the tape.* This cut the number of records on the tape file from $512 * 512=262,144$ to only 68,227, permitting the complete file to reside on one tape, and considerably reducing the time and effort involved for data manipulations.

Some time and distance entries on the tape have been set to a "flag value" of 99999. This means that the connection via the associated transportation mode for that particular zone pair either does not exist or is so expensive to use as not to be a serious consideration. It is important to bear in mind that one flagged value does not completely remove a link from consideration in the "zero flow" sense described earlier. There are six modes of transportation available between pairs. So long as even one of these is not flagged, the link is still a valid connection.

NET80 and NET9O are copies of NET70, but with all flows expanded by Fratar projection so that they are predictions of 1980 and 1990 movement levels. The time and distance entries are the same on all three tapes, the only differences being in the commodity class flow entries.

Appendix A contains a succinct description of the computer format of the three tapes discussed in this section.

*This step is not irreversible. Zones could be reconnected, with a positive flow, by use of a simple edit program. 



\section{THE MODAL-SPLIT PROGRAMS--SPLIT}

SPLIT is a subroutine whose inputs are the records from NET70 and whose outputs are records in which the commodity flows have been allocated among the available modes of transportation. In other words, whereas NET70 contains what must be shipped from zone to zone, SPL70 (the output tape from a modal-split run) shows how much of each commodity will be shipped by each mode.

The basic idea in a modal split is to compute a set of "weights" $u_{i j}, i=1,2, \ldots, 8$, and $j=1,2, \ldots, 6$, satisfying

$$
\sum_{j=1}^{6} u_{i j}=1
$$$$
\text { for alli }
$$

These weights can then be used to distribute commodity $i$ among the possible modes $j$. The model used to compute the weights in subroutine SPLIT is given by

$$
\omega_{i j}=e^{\rho_{i j}}\left[c_{i j}\left(d_{j}\right)\right]^{\beta_{i j}} t_{j}{ }^{\alpha},
$$

where $d_{j}$ and $t_{j}$ are the distance and time associated with transportation mode $j,{ }^{j} c_{j j}()$.$j is a cost function dependent on distance, and \alpha, \beta$, and $\rho$ are parameters, and $e$ is the base of the natural logarithms. The weights are obtained by normalizing the $\omega_{i j}$ :

$$
u_{i j}=\omega_{i j} / \sum_{k=1}^{6} \omega_{i k}, \quad \text { for all } i .
$$

More on the general concept of modal splitting, this particular choice of a model and the calibrations performed to choose appropriate values of $\alpha, \beta$, and $\rho$ can be found in [4]. This brief account is included here only to provide the programmer/user with background information on the theoretical foundation for subroutine SPLIT.

The key to understanding the inner workings of SPLIT, is to recall that the NNDBS involves 8 commodity classes and 6 modes of transportation, and to note that not all modes are available to all commodities. For example, the only commodity. that can be transported via the crude oil pipeline is, of course, crude oil. There are other combinations that are theoretically possible, but in practice are not used because cost is prohibitive; an example is sending crude oil by air. The complete picture of possible connections is given in Figure 2, where a " 0 " indicates a usage which is impossible (in the sense outlined above) and a "l" indicates a valid connection. 
Transportation Modes

\begin{tabular}{lcccccc}
$\begin{array}{l}\text { Commodity } \\
\text { Classes }\end{array}$ & Truck & Rail & Air & Water & $\begin{array}{c}\text { Crude } \\
\text { Pipeline }\end{array}$ & $\begin{array}{c}\text { Refined } \\
\text { Pipeline }\end{array}$ \\
\hline High large $\left(^{*}\right)$ & 1 & 1 & 0 & 1 & 0 & 0 \\
High small & 1 & 1 & 1 & 0 & 0 & 0 \\
Medium large & 1 & 1 & 0 & 1 & 0 & 0 \\
Medium smal1 & 1 & 1 & 0 & 0 & 0 & 0 \\
Low large & 1 & 1 & 0 & 1 & 0 & 0 \\
Low small & 1 & 1 & 0 & 0 & 0 & 0 \\
Crude large & 0 & 0 & 0 & 1 & 1 & 0 \\
Refined large & 1 & 1 & 0 & 1 & 0 & 1
\end{tabular}

*) "High" (or "medium" or "low") refers to dollar-value per unit for the ommodity class; "large" or "small" refers to shipment size.

FIGURE 2: THE MATRIX OF POSSIBLE CONNECTIONS 

To facilitate program organization, it was decided to store $\omega_{i j}$ as a one-dimensional "packed" Tist (OMEGA) corresponding to the matrix given in figure 2, but with all elements whose value is zero removed from consideration. Since the same storage scheme was applied to $a_{j j}$, $\beta_{j j}$ and $\rho_{j j}$, there was no problem in matching the correct values of those arrajs with $\omega_{i j}$ for a modal-split computation. However, with this storage scheme, the simple row-column indexing that would yield commodity class and transportation mode is not available. That information is needed to sum across modes for a given commodity, and to retrieve correct distances for flag-value checking.

The row indexing required in SPLIT is provided by the array COMIND (see the listing in Appendix G). For any $I=1,22$, Comind (I) is the commodity class reference (row number in Figure 2) for the corresponding element I of the arrays OMEGA, ALPHA, BETA, and PHO.

It turns out that transportation-mode indexing (column number in Figure 2) is not required in SPLIT. What is required is retrieval, for each element of OMEGA, of the distance to be traveled by the commodity quantity in question. This retrieval information is provided by the array DSTIND (again, see the listing in Appendix G). For $I=1,22$, DSTIND (I) is an index into the input record (array IR) where the desired distance can be found.

The last indexing array to be explained is the one represented by CSTIND, which is an indexing scheme for the cost functions. For each of the pipeline refined, pipeline crude, water and air modes of transportation, there is a cost function to be applied to a 17 commodities shipped by that mode. Rail and truck, however, have three cost functions, the applicable one depending on whether the shipment is high value, medium value, or low value, according to a prescribed classification scheme. This yields a total of 10 cost functions, and these are stored in the array COST. Therefore CSTIND (I), for each $I=1,22$, is an index into COST for retrieving the correct cost function to be used in the modal-split computation.

It must be expected that cost functions will change over time. Moreover, their number can also change (e.g., a disaggregation of the "water" mode might be used for some studies). Given the indexing scheme for the cost functions outlined above, implementation of any such changes would be simple and straightforward.

The actual work of "splitting" the flows is now straightforward. SPLIT works on one record at a time from NET70, MET80 or NET90. First it computes the costs to be stored in COST, which are based on the interzonal travel distances by each mode. It then launches into the computation of the weights $\omega_{i j}$, relying on the indexing presented above. Having done so, it splits each commodity-class flow among the available modes by multiplying by the weights. An output record is then created following the computer format given in Appendix D, and that record is passed back to the main program, along with control. 
The main driving program which controls the modal-split run is concerned with reading in from the input network tape (NET70, NET80, NET90), mounted on logical unit 7 , a block of 100 records, and passing each record off to subroutine SPLIT. After processing is complete for the block of 100, the driver writes the "splitted" version of the records onto the output SPLIT tape (SPL70, SPL80, or SPL90), mounted on logical unit 8 , and goes back to read in the next block of 100 records. The data blocks are transferred by a UNIVAC 1108 software package (NTRAN) which performs binary transfers of blocks of any size.

The printer output from a modal split run consists of a table giving accumulations by ton, ton-mile, and revenues, plus a second table giving sums over all fields of the output tape. Both tables are useful for checking purposes.

There is another capability that has been provided in the driver program for SPLIT. It is an option to read an alternate set of impedances from a tape mounted on logical unit 9. This alternate tape could be NETTS (see Appendix C), or another tape with similar format. This capability is useful for testing and experimentation purposes. It could, for example, be used in discovering the effect of adding and deleting links from the network. To make use of this capability one simply creates the "alternate impedance tape", mounts it on unit 9 along with the normal input and output network tapes on units 7 and 8 , and changes the value of the logical variable ALT in the driver program from .FALSE. to . TRUE.

Note that it is not necessary to carry the complete set of impedances on the alternate impedance tape. One may desire to change only the highway impedances or only those for rail, or some combination. The point is that the alternate tape need only carry information that is changed. Program changes, to accommodate such partial modifications of the impedances, are required only in 7 ines 19 and 20 of the driver program for SPLIT. For example, suppose it is desired to change the rail impedances, but keep a11 others fixed. One then creates an alternate tape with 68,227 logical records, each one containing four words: the origin WNS zone, the destination NWS zone, the (new) rail distance, and the (new) rail time. Lines 19 and 20 of the driver program would then be changed from the existing Do loop to the following:

$$
\begin{aligned}
& \operatorname{IR}(5, J)=\operatorname{AR}(3, J) \\
& \operatorname{IR}(6, J)=\operatorname{AR}(4, J)
\end{aligned}
$$


STAG is a subroutine whose inputs are records from one of the "split tapes" (SPL70, SPL80, or SPL90), and whose outputs are a set of matrices showing: a) the average daily flow of goods by commodity-class among the 50 states, the District of Columbia, and the U. S. possessions; and b) the costs of transporting that amount of goods.

Just as with SPLIT, STAG is the major routine which does the aggregation on individual logical records that have been passed to it by the driver routine. The driver does all the tape handling and the breakdown of the blocks to logical records. Since STAG's driver is similar to SPLIT's, discussed in Section 3, the rest of the discussion in this section will be confined to subroutine STAG.

The key to understanding STAG lies in Figure 3 , which shows which NNS zones are mapped into which states. For example, the top line indicates that all flows originating from NNS zones 1 through 5 should be aggregated to represent a total flow originating from Maine. The meaning of the "partial zones" column is straightforward: the specified percentages of the flows for the given zones are to be aggregated to make up the flow to or from the associated state. The need for this column arises because some NNS zones cross state boundaries. The percentages are based on total population figures and were obtained from Allan 01 son of the Bureau of Economic Analysis, U.S. Dept. of Commerce.

The manner in which the mapping scheme is implemented in STAG, however, is the inverse of the mapping described in Figure 3. That is, for a given I ranging from 1 to 512 (the NNS zone numbers that appear on the NNDBS tapes), NDX(I) is the state number to which the flows from NNS zone I should be added. If $\operatorname{NDX(I)}$ is negative, $A B S(N D X(I))$ is a pointer to a row in the arrays PCT and NPCT which respectively contain the percentages and the states to which the percentage flows are to be added.

There are 10 matrices that are created by STAG. They represent, respectively, the volumes of flow and the cost of transporting that flow, among the states for the following situations:

1.) high value shipments, both large and small,

2.) medium value shipments, both large and smali,

3.) Tow value shipments, both large and smal1,

4.) a 71 crude $0 i 1$ shipments, and

5.) al1 refined oil shipments.

As each record is passed into STAG by the driver, the amount to be added to each one of the 10 matrices is computed in turn and control is 


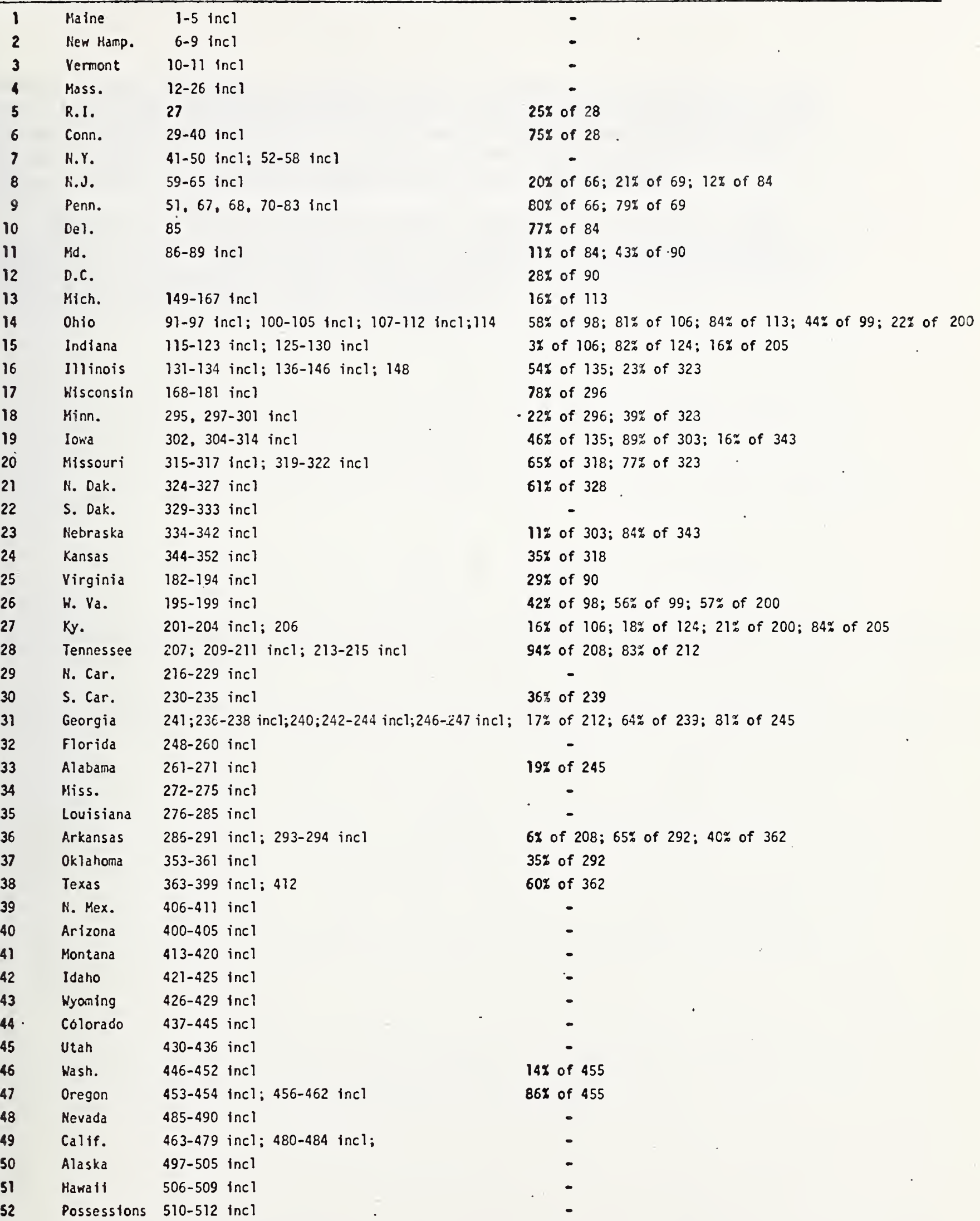

FIGURE 3: MAPPING FROM N.VS ZONE TO STATE. 


\section{.}


passed to the internal subroutine ADD. ADD does all the work of stepping through the indexing scheme so that the additions are made to the proper element of each matrix. When each of the 10 matrices has been properly adjusted for the record at hand, control is returned to the driver routine which gets the next record to be processed.

When the last record from the input tape file is reached, STAG closes out the run by computing and printing out row and column sums for each matrix. The driver then writes the matrices onto logical unit 8 according to the format given in Appendix E. 



\section{THE BEA ZONE AGGREGATION PROGRAMS--BAG}

The BAG programs are very similar in form and content to the programs discussed in Section 4. In these programs, however, the aggregation is by BEA zone (see $[3,4]$ for a discussion of BEA zones), rather than state, and there are 16 matrices (described below) computed rather than just 10 . These two changes required several alterations to the basic programs written to handle the state aggregations. One such change had to do with storage: there are 174 BEA zones, so that the 16 matrices (with row and column sums) require $16 * 175^{*} 175=490,000$ words just for data storage. Since that is more than the NBS UNIVAC 1108 can store "in core", the programs were modified to compute one matrix at a time with one pass through the data tape, then to rewind and compute another, and so on.

Another necessary modification concerned the structure of what were called in STAG the PCT and NPCT tables. Recall that these tables provided the indexing and percentages for those zones that crossed state boundaries. The same situation obtains here, but in BAG, the two tables have been combined and more information has been stored in the resultant table.

The following discussion refers to two arrays: PCT and IPCT. These two arrays have been "equivalenced: so that both integer and real values can be stored in adjacent words of the same array. Letting I be an NNS zone number, then as before NDX(I) is the BEA zone number to which the flows to and from NNS zone I should be added. But if $N D X(I)<0$, then letting IAD=-NDX(I), we now have that IPCT(IAD) contains two numbers "packed" into the same word. The leftmost number, retrieved by letting NL=IPCT(IAD)/1000, is a pointer back into NDX. The rightmost number, retrieved by letting NR=IPCT(IAD) $-N L * 1000$, is the number of BEA zones that are intersected by NNS zone I. There will be NR groups of 3 words each in the PCT table following word IAD. In each group, the third word is the zone number of one of the BEA zones intersected by NNS zone I. The second word is the proportion of total earnings of NNS zone I that accrued from that BEA zone, and the first word is the proportion of total income of NNS zone I that accrued from the BEA zone. The income proportion is used in the aggregation when the NNS zone in question appears as a destination zone in the input record from the split tape. The earnings proportion is used when the zone appears as an origin in that record.

The DATA statements in BAG that initialize the PCT table were created by a set of programs not included in the NNDBS. Documentation of those programs, and the source of the earnings and income proportions used in the DATA statements, appears in reference [3]. 
The subroutine BAG works similarly to STAG. A logical record is passed into it, volume or costs are computed and aggregated, and the internal subroutine ADD is called to step through the indexing scheme and add the quantities to the proper element of the matrix currently being computed. The number (1-16) of the matrix being computed is passed in the calling sequence in the variable $M$, and the matrix itself is passed in BMTX.

The matrices computed correspond respectively to the volume and cost matrices for the same eight commodity classes listed in Section 2.

The only major difference between the driver program for $B A G$ and that for STAG is that the computation of each matrix in BAG requires one complete pass through the tape. After each matrix is computed, its row and column sums are computed, it is dumped out in binary form on unit 8 , the input tape (unit 7) is rewound, and the next phase of matrix computation is begun.

The computer format of the output tape from a run of $B A G$ is given in Appendix F. 


\section{.}




\section{CONCLUSION}

The National Network Data Base System was designed with one main goal in mind: to provide a maximum of useful data on the inter-city freight and passenger flows along the major transportation network of the United States, while keeping the number of data words actually stored to a minimum. This approach also permits a great deal of flexibility in data-base usage: a capability to change easily the modal split equation, to revise cost functions, to aggregate over a slightly modified index set, to modify the network, and so on.

In fact, this ability to exercise the data-base system and to derive a set of data different from that built into it has already been used successfully. A request was made to compute state and BEA zone aggregations for 1972, a year for which no flow data existed in the data base. What was provided, however, was a set of state and BEA zone growth rates from 1970 to 1972 , based on total earnings and tota 7 income for the states and BEA zones. The request was satisfied with ease by - applying the given growth rates to the row and column sums of the matrices already produced in the system, normalizing the new sums with respect to the "expanded grand total" of the matrices, and then using a standard matrix scaling algorithm $(*)$ to adjust the elements to the new sums.

This is one of the many possible examples of the flexibility of such a data base "system". Other uses are anticipated.

(*) The program (SCALE) is a part of NBS's Mathematical Programming Algorithms collection and is based on the procedure outlined on p. 115 of [1]. 


\section{BIBLIOGRAPHY}

1. Deming, W. E., Statistical Adjustment of Data, John Wiley and Sons, New York, 1938.

2. Fratar, T. J., "Vehicular Trip Distribution by Successive Approximations", Traffic Quarterly, Vol. VIII, No. 1, January 1954, pp. 53-65:

3. Lozier, D. W., and Stiehler, J. R., "Machine-Readable Mapping from National Network Simulation (NNS) Zones to Bureau of Economic Analysis (BEA) Areas", NBSIR 75-918, September, 1975.

4. Schofer, R., "Final Report on the National Network Simulation", NBSIR 75-912. (in preparation)

5. U. S. Department of Transportation, FHWA Computer Programs for Urban Transportation Planning, July, 1974. 

APPENDIX A: COMPUTER FORMAT OF NET70, NET80, AND NET9O

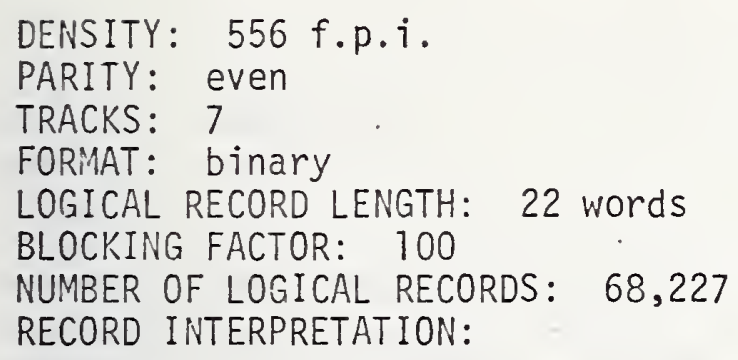

Origin NNS zone 0

Destination NNS zone D

Distance by truck (mi) TD

Time by truck (min.) . TT

Distance by rail RD

Time by rail RT

Distance by air AD

Time by air AT

Distance by water WD

Time by water WT

Distance by crude pipeline PCD

Time by crude pipeline PCT

Distance by refined pipeline PRD

Time by refined pipeline PRT

Large, high value shipment volume (tons). HL

Smal1, high value shipment volume (tons) HS

Large, medium value shipment volume (tons) ML

Sma11, medium value shipment volume (tons) MS

Large, low value shipment volume (tons) LL

Small, low value shipment volume (tons) LS

Large, crude oil shipment volume (tons) CL

Large, refined oil shipment volume (tons) RL 
APPENDIX B: COMPUTER FORMAT OF THE PASSENGER TAPE--NETPS

DENSITY: 556 f.p.i.

PARITY: even

TRACKS: 7

FORMAT: binary

LOGICAL RECORD LENGTH: 14 words

BLOCKING FACTOR: 100

NUMBER OF LOGICAL RECORDS: 54,128

RECORD INTERPRETATION:

WORD

MEANING

1

2

3

4

5

6

7

8

11

12

13

14

Origin NNS zone number

Destination NNS zone number

Distance by auto $\left(m_{i}\right)$

Time by auto (min.)

Number of daily auto passengers, non-business purposes

Number of daily auto passengers, business purposes

Distance by air (mi)

Time by air (min.)

Number of daily air passengers, non-business purposes

Number of daily air passengers, business purposes

Distance by rail (mi)

Time by rail (min.)

Number of daily rail passengers, non-business purposes

Number of daily rail passengers, business purposes. 
APPENDIX C: COMPUTER FORMAT OF THE ALTERNATE IMPEDANCE TAPE--NETTS

DENSITY: 556 f.p.i.

PARITY: even

TRACKS: 7

FORMAT : binary

LOGICAL RECORD LENGTH: 14

BLOCKING FACTOR: 100

NUMBER OF LOGICAL RECORDS: 68,227

RECORD INTERPRETATION: Exactly the same as the first 14 words listed in Appendix A. 
DENSITY: 800 f.p.i.

PARITY: even

TRACKS: 7

FORMAT: binary

LOGICAL RECORD LENGTH: 37 words

BLOCKIIVG FACTOR: 100

INUPABER OF LOGICAL RECORDS: 68,227

RECORD INTERPRETATION:

WORD

MEANING

SYMBOL

1 Origin Whs zone 0

2 Destination Nis zone D

3 Distance by truck $\left(m_{j}\right)$ TD

4 Time by truck (min.) TT

5 Distance by rail RD

6 Time by rail RT

7 Distance by air $\quad A D$

8 Time by air AT

9 Distance by water WD

10 Time by water WT

11 Distance by crude pipeline PCD

12 Time by crude pipeline PCT

13 Distance by refined pipeline PRD

14 Time by refined pipeline PRT

15 Tons of high value, large shipments sent by truck THL

16 Tons of high value, small shipments sent by truck THS

17 Tons of medium value, large shipments sent by truck

18 Tons of medium value, small snipments sent by truck

19 Tons of low value, large shipments sent by truck

20 Tons of low value, small shipments sent by truck

21 Tons of large, refined oil shipments sent by truck

22 Tons of high value, large shipments sent by rail

23 Tons of high value, small shipments sent by rail

24 Tons of medium value, large shipments sent by rail

25 Tons of medium value, small shipments sent by rail

26 Tons of low value, large shipments sent by rail

27 Tons of low value, small shipments sent by rail

28 Tons of large, refined oil shipments sent by rail

29 Tons of nigh value, small shipments sent by air

30 Tons of high value, large shipments sent by water

31 Tons of medium value, large shipments sent by water

32 Tons of low value, large snipments sent by water

33 Tons of large, crude oil shipments sent by water

34 Tons of large, refined oil shipments sent by water

35 Tons of large, crude oil shipments sent by pipeline

36 Tons of large, refined oil shipments sent by pipeline

37 Sum over fields 15 through 37

TML

TMS

TLL

TLS

TRL

RHL

RHS

Rill

RH'S

RLL

RLS

RRL

AHS

WHL

则

WS

$W C L$

WRL

PCL

PRL 


\section{APPENDIX E: COMPUTER FORMAT OF THE STAG TAPES--STG70, STG80, AND STG90}

DENSITY: 556 f.p.i.

PARITY: even

TRACKS: 7

FORMAT: binary

LOGICAL RECORD LENGTH: 2809

BLOCKING FACTOR: 0

NUMBER OF LOGICAL RECORDS: 10

RECORD INTERPRETATION: Each record contains one of the $53 \times 53$ matrices created by STAG, written out columin by column. They are, in order of appearance on the tape, state-to-state aggregations of the following:
1) high value, large and small flows (tons).
2) the transport costs of number 1 (dollars),
3) medium value, large and small flows,
4) the transport costs of number 3 ,
5) low value, large and small flows,
6) the transport costs of number 4,
7) crude oil flows,
8) the transport costs of number 7,
9) refined oil flows,
10) the transport costs of number 8.

Reference Figure 3 for which state is associated with each row and column number. The row and column sums appear in the last row and column. 


\section{.}




\section{APPENDIX F: COMPUTER FORMAT OF THE \\ BAG TAPES--BAG70, BAG80, AND BAG90}

DENSITY: 556 f.p.i.

PARITY: even

TRACKS: 7

FORMAT : binary

LOGICAL RECORD LENGTH: 30625

BLOCKING FACTOR: 0

NUMBER OF LOGICAL RECORDS: 16

RECORD INTERPRETATION: Each record contains one of the $175 \times 175$

matrices created by BAG, written out in column order. The matrices are, in order of appearance on the tape, BEA zone to BEA zone aggregations of the following:

1.) high value, large flows (tons),

2.) the transport costs of number 1 (dollars),

3.) high value, smali flows,

4.) the transport costs of number 3,

5.) medium value, large flows,

6.) the transport costs of number 5,

7.) medium value, small flows,

8.) the transport costs of number 7 ,

9.) low value, large flows,

10.) the transport costs of number 7 ,

11.) low value, small flows,

12.) the transport costs of number 9,

13.) crude oil flows,

14.) the transport costs of number 13,

15.) refined oil flows,

16.) the transport costs of number 15 . 


\section{APPENDIX G: LISTING OF THE \\ SPLIT PROGRAMS}


ARUN, N/R RICJAK, 36131-JACKSO,BEA,15,100, ח2nND

EMST,W 33131-JACKSO MRITE ENABLE REFL SPL7ח•

AMSG THANKS...RIC

AASG, TJM 7 , $11, N E T 70$

GASG,T JH 8 . , 11, SPL $70 W$

RASG, AX SUR.

BASG, AX DRV.

GFOR,S DRV. SDL.IT, TPF \$.A

DFOR, S SUR.SPLIT,TPF.$A$

OFREF SUR.

WFFEE DRV •

QXXT

DCHARGE

END ONSITE PRINTOUT ON OCTORFR 6, 1975 AT $13: 42: 49$

$B E A * R U N(1)$. SPLIT(5) 


\section{LISTING OF URIVER FOR SUEROUTINE SPLIT}

PARAMETER MIR $=22, M O R=37, M A R=1$

IMPLICIT INTEGER $(A-Z)$

LOGICAL ALT

DIMENSION IR (MIR, 100), OR $(M O R, 100)$, S (MOR), AR (MAR, 100)

DATA ALT/.FALSE./

WRITE $(6,6)$

C*\#\#* READ A ELOCK FROM THE INPUT TAPE.

10 CALL NTRAN $(7,2, M I R * 100, I R(1,1), L, 22)$

IF $(L . L T . O)$ GO TO 80

C* IF NECESSARY, READ BLOCK FROM ALTERNATE TAPE.

IF (ALT) CALL NTRAN $(9,2, M A R * 100, A R(1,1), N, 22)$

IF $(N . L T . O)$ GO TO 100

C*** BEGIN LOOP HHICH PASSES OFF EACH LOGICAL RECORD, IN TURN,

C** TO THE SUSROUTINE FOR PROCESSING.

DO 50 Je1, 100

IF (.NOT.ALT) GO TO 30

IF $(I R(1, j), N E$. AR $(1, j), O R$. IR $(2, j)$,NE.AR(2,J)) GO TO 110

C**** IF ALTERNATE TAPE UP AND RECORDS MATCH. TRANSFER THE IMPEDANCES. DO 20 I=1 MMAR

$20 I R(I, J)=A R(I, J)$

$30 \mathrm{C}=\mathrm{C}+1$

CALL SPLIT(IR (I, J),MIR,OR (I,J),MOR)

C*** IF FIRST HORD IS ZERO, LAST BLOCK ON TAPE HAS BEEN REACHED. IF $(I R(1, J), E Q \cdot 0)$ GO TO 900

C**** SUM ELL FIELDS OF OUTPUT TAPE.

DO 40 IEI,MOR

$40 S(I)=S(I)+O R(I, J)$

50 CONTINUE

C**** HRITE A BLOCK TO THE OUTPUT TAPE.

60 CALL NTRAN $(8,1, M O R * 100,0 R(1,1), M, 22)$

IF $(M . L T, O)$ GO TO 90

$0070 \quad I=1, M O R$

DO $70 \mathrm{~J}=1.100$

$70 O R(I, J)=0$

GO TO 10

80 WRITE $(6,2)$ L,C

GO 70900

90 HRITE $(6,1)$ M.C

GO TO 900

100 WRITE $(6,7)$ N.C

GO TO 900

110 HRITE $(6,8)$

C**** WRITE OUT LAST BLOCK AND ENDFILE.

900 CALL NTRAN $(8,1, M O R * 100, O R(1,1), M, 22)$

CALL NTRAN $(8,9)$

WRITE $(6,4)$ C

WRITE $(6,5)$

WRITE $(6,3) \quad(I, S(I), I=1, M O R)$

1. FORMAT ( * ERROR $M=115, \cdot C=115)$

2 FORMAT (1 * ERROR L $=115,1 C=115)$

3 FORMAT $(2 \times 15,115)$

4 FORMAT(/1XI10,' LOGICAL RECORDS WERE TRANSFERRED,")

5 FORMAT(// SUM OVER ALL OUTPUT TAPE FIELDS'///2X'FIELD'12X'SUM")

6 FORMAT ('1')

7 FORMAT( $*$ ERROR $N=1$ I5, $C=1$ I5)

8 FORMAT (' * ERROR C='I5," TAPE RECORDS DO NOT MATCH.')

END 

SUBROUTINE SPLIT (IR,MIR,ORPMOR)

LOGICAL NFIRST

INTEGER OR, COMIND,CSTIND,DSTIND, TYPE. SUMNO, SUMTN, SUMTM

INIEGER SUMRV

DIMENSION IR (MIR) , OR (MOR), ALPHA (22), BETA (22), RHD (22), OMEGA (22)

DIMENSION COST $(10) \cdot \operatorname{CSTINO}(22)$. DSTIND $(22) \cdot \operatorname{COMIND}(22) \cdot \operatorname{SUM}(8)$

DIMENSION TYPE(22), SUMNO(22), SUMTN(22), SUMTM(22), SUMRV(22)

DIMENSION R(3)

DATA NFIRST/.FALSE./

DATA RHO/7.8124.15.4762.8.1321.10.\$584.6.9884.8.0848.19.0570.1.0.

*

*
*

* *

*

DATA TYPE/ TH $1.0 \cdot 1.0 .1 .0 .1 .0 .1 .0 \cdot 1.0 .07 .4047 \cdot .6019 \cdot 1.4242 .0 .0638$. $1.0 .0768 \cdot 8.623 \cdot 1.8 /$

DATA BETA/ $0.9299,-3.2584,0.9299,-.869,-1.4726,-.869,-2.785,-.21921$ $-2.11040=.2192,=.2288 p-.7732,0.2288,-1.11860-1.56261$

$=.4888,0.4886,0.7498,-.2466,-.9052, \cdots .7928,-.8466 /$

DATA ALPHA/ $=.2944,=1.4294,0.2944,-.8458,-.5545,-.8458,-1.3691$. $0.0 .0 .7922 \cdot 0.010 .5756,-.2251,-.5756,-.6018 \cdot-.1332$.

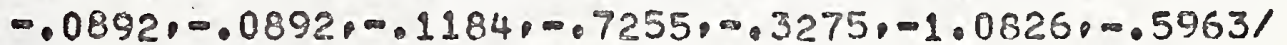

$*$

* 'RHS "RML ' 'RMS', 'RLL' PRLS', PRRL' PAHS' "WHL', 'HAL PWLL, PWCL P WRL PPCL',PPRL, /

DATA COMIND/1.2.3,4.5.6.8.1.2.3.4.5.6.8.2.1.3.5.7.8.7.8/

DATA CSTIND/1.1.2.2.3.3.3.4.4.5.5.6.6.6.7.8.8,8.8.8.9.10/

DATA DSTIND/3.3.3.3.3.3.3.5.5,5,5,5,5,5,7,9,9,9,9,9,11,13/

C**** CHECK IF THIS IS LAST LOGICAL RECORD.

IF (IR (I).EQ.0) GO TO 800

IF (NFIRST) GO TO 100

C**** IF FIRST TIME THROUGH, RESET RHO.

DO 10 I=1:22

10 RHO(I) $=E X P(R H O(I))$

NFIRST:.TRUE.

C**** COMPUTE COSTS (PENNIES/TON):C $C(1)-C(10)$ ARE, IN ORDER:

C*** CTH,CTM,CTL,CRH,CRM,CRL,CA,CH,CC,CR .

$100 \operatorname{COST}(1)=.8817 *(-1216.0+924.0 * I R(3) * .421)$

$\operatorname{CosT}(2)=.4961 *(-1216.0+924.0 * I R(3) * .421)$

$\operatorname{cosT}(5)=.4188 *(-1216.0+924.0 * I R(3) * .421)$

$\operatorname{cosT}(4)=718 \cdot+2 \cdot 95 * I R(5)$

$\operatorname{cosT}(5)=341 \cdot+1 \cdot 70 * I R(5)$

$\cos T(6)=21 \cdot 4+1 \cdot 47 * I R(5)$

$\operatorname{COST}(7)=10540 .+18.92 * I R(7)$

$\operatorname{CosT}(8)=296 \cdot 5+.644 * I R(9)$

$\operatorname{cosT}(9)=25.84+.2324 * I R(11)$

$\operatorname{CosT}(10)=.4148 * I R(13)$

$R(1)=1349.5251+3.5187860 * I R(3)$

$R(2)=992.43256+3.1580756 * I R(3)$

$R(3)=768.85476+2.6590308 * I R(3)$

DO $150 \quad I=1,3$

$\operatorname{COST}(I)=M I N(M A X(\operatorname{COST}(I), R(I)), 1 \cdot 17 * R(I))$

150 CONTINUE

C*** COMPUTE THE UNNORMALIZEO WEIGHTS.

200 DO $210 \quad I=1.22$

OMEGA $(I)=0.0$

$J 1=D S T I N D(I)$

IF (IR(J1).GE.99999.OR.IR(J1+1).GE.99999) G0 TO 210 $12=\operatorname{CSTIND}(I)$

IF $(\operatorname{COST}(J 2) \cdot E Q \cdot 0.0 .0 R \cdot I R(J 1+1), E Q \cdot 0)$ GO TO 210

OMEGA $(I)=R H O(I) * \operatorname{COST}(J 2) *$ BETA $(I) * F L O A T(I R(J 1+1)) * * A L P H A(I)$

210 CONTINUE 
LISTING OF SUBROUTINE SPLIT

C** SUM THE HEIGHTS ACROSS MODE TO GET NORMALIZING FACTOR. DO $310 \quad I=1.8$

$310 \operatorname{SUM}(1)=0.0$

DO $320 \quad I=1,22$

JECOMIND(I)

320 SUM(d) $=5$ UM (d) +OMEGR(I)

C***\% NORMALIZE THE WEIGHTS.

DO $420 \quad \square=1.22$

$J=C O M I N D(I)$

IF (SUM(J).GT.0) GO TO 420

OHEGA $(I)=0.0$

GO TO 42.0

410 OMEGA(I) OOMEGA (I)/SUM(J)

420 CONTINUE

C**** SPLIT THE SHIPHENTS BY MULTIPLYING THEM BY THE WEIGHTS.

DO $510 \quad I=1.22$

$J=C O M I N D(I)+94$

510 OMEGA (I) $=0$ OMEGA (I) *FLOAT IR (J))

C**** BUILD THE OUTPUT RECORD.

DO $620 \quad I=1.14$

610 OR $(I)=I R(I)$

$O R(39)=0$

DO $620 \quad I=1.22$

$O R(I+14)=O M E G A(I)+.5$

$620 O R(37)=O R(37)+O R(I+14)$

C**** SUM THE TONS. TON-MILES, AND REVENUES.

DO $720 \quad I=2.22$

J\&EDSTIND (I)

IF (IR(J1).GE.99999) 60 TO 720

SUMTM(I) $=$ SUATM $(I)+O R(I+14) * I R(J 1)$

J2ECSTIND (I)

SURRV $(I)=S U M R V(I)+O R(I+14) * \operatorname{COST}(J 2)$

SUMTN $(I)=$ SUMTN $(I)+O R(I+14)$

SUMNO (I) $=$ SUMNO $(I)+1$

720 CONTINUE GO PO 999

C**** OUTPUT THE TABLE OF SUMS.

800 VRITE $(6,1)$

HRITE $(6,2)$ (TYPE(I),SUMNO (I),SUMTN(I), SUMTM(I),SUMRV (I),I=1,22)

1 FORHATI/12X. TOTAL 7X'TOTAL'11X'TOTAL'10X'TOTAL'/1X'TYPE'7X ' COUNT' $8 X$ 'TONS $7 X$ TON-MILES $7 X$ TREVENUES / / /

2 FORMAT $(2 X A 3, I 12,112, I 16, I 15)$

999 RETURN

END 
APPENDIX H: LISTING OF THE

STAG PROGRAMS 
LISTING OF CONTROL STREAM FOR A RUN OF STAG

RRUNOM/R RICJAK' 36131-JACKSO,BEAP 50100 DASG PAX DRV. DASGBAX SUB. DASG,A STOUT. DASG,TJH T.,U.SPLTO QUSE 8. DTOUT. DFORPS DRV.STAG,TPFS.A DFOR,S SUB.STAG,TPF $\$ \cdot B$ DFREE DRV. AFREE SUB. QXXT

ACOST 
PARAMETER MIR $=37, M V D=53$

INTEGER C

DIMENSION IR (MIR, 100)

DIMENSION VOLS (MVD,MVD.5), DOLS (MVD,MVD.5)

C*** READ A BLOCK FROM INPUT TAPE.

10 CALL NTRAN $(7,2, M I R * 100, I R(1,1), L, 22)$

IF $(L . L T . O) \quad 6 O$ TO $B O$

C* BEGIN LOOP TO PASS OFF EACH LOGICAL RECORD TO SUBROUTINE. DO $50 \mathrm{~J}=1.100$

CALL STAG(IR (1,J), VOLS,DOLS)

IF $(I R(1, J) \cdot E Q \cdot 0)$ GO TO 100

$C=C+1$

50 CONTINUE

GO TO 10

80 WRITE $(6,2)$ L.C

C**** WRITE OUT AGGREGATED MATRICES ONTO UNIT 8 .

100 DO $110 \mathrm{~K}=1.5$

CALL NTRAN $(8,1, M V D * M V D, V O L S(1,1, K), M, 22)$

110 CALL NTRAN $(8,1, M V D * M V D, O O L S(1,1, K), M \cdot 22)$

CALL NTRAN $(8,9)$

C*** PRINT OUT ROW AND COLUMN SUMS.

DO $150 \quad K=1.5$

WRITE $(6,3) \mathrm{K}$

WRITE $(6,4)$ (VOLS $(I, M V D, K), I=1, M V D)$

WRITE $(6,5) \mathrm{K}$

WRITE $(6,4)$ (VOLS $(M V D, I, K), I=1, M V D)$

WRITE $(6,6) \mathrm{K}$

WRITE $(6,4)$ (DOLS $(I, M V D, K), I=1$,MVD)

WRITE $(6,7) \mathrm{K}$

150 WRITE $(6,4)$ (DOLS $(M V D, I \circ K), I=1, M V D)$

2 FORMAT $(1 *$ ERROR L $=115, \cdot C=15)$

3 FORMAT (/1 ROW SUMS FOR VOLUME MATRIX NUMBER I $13 /$ )

4 FORMAT (10 (E13.7))

5 FORMAT $/ 1$ COLUMN SUMS FOR VOLUME MATRIX NUMBER'I3/)

6 FORMAT (/1 ROW SUMS FOR COST MATRIX NUMBER'I3/)

7 FORMAT $/ /$ COLUMN SUMS FOR COST MATRIX NUMBER'I3/)

END 


\section{.}


SURROUTIIIE STAG(IR, VOLS, DOLS)

DI MENSIOI! VOLS $(53,53,5)$, ONLS $(53,53,5)$

OI MENSIO: IR(37), PCT $(26,3)$, NPCT $(26,3), M D \times(51.2)$

DATA $((P C T(1, J), M D C T(1, J), J=1,3), 1=1,19)$,

\begin{tabular}{|c|c|c|c|c|c|c|}
\hline & .25 , & 5 , & .75 , & 6 , & .00 , & $c$, \\
\hline 2 & , 20 , & 8 , & $.8 \mathrm{C}$, & 9 , & - $\triangle \mathrm{C}$, & $c$, \\
\hline 3 & .21 , & 8 , & .79, & 9 , & , & $c$, \\
\hline 4 & .12 , & 3 , & .77 , & 10, & .11 , & 11, \\
\hline 5 & .43, & 11, & .29, & 12, & .79 , & 25, \\
\hline 6 & .58, & 14, & .42 , & 26, & .00 , & C, \\
\hline 7 & .44, & 14, & .56, & 26, & , & C, \\
\hline 8 & .81 , & 14, & .03, & 15, & .16 , & 27, \\
\hline & .16 , & 13, & .84, & 14, & .20 , & o, \\
\hline & .32 , & 15, & - IB, & 27, & . no, & o, \\
\hline 1 & .54, & 16, & .46 , & 19, & . $\cap$, & C, \\
\hline 2 & . 22, & 14 & .57, & 26, & .21, & 27, \\
\hline 3 & .16, & 15, & .84 , & 27, & . co, & 0, \\
\hline 4 & .94, & 28, & $\cdot \square 6$, & 36 , & סחת. & D, \\
\hline 5 & .83 , & 28, & .17 , & 31 , & , & 0 , \\
\hline 6 & .36 , & 30, & .64, & 31, & $\cap \cap$, & 0 , \\
\hline 7 & .91 , & 31 , & .10, & 33, & - 50 , & 0 \\
\hline 8 & .65 , & $3 b$, & .35 , & 37, & - C, & \\
\hline & .78, & 17, & .22. & 18, & & \\
\hline
\end{tabular}

DATA $((P C T(1, J), N P C T(1, J), J=1,3), 1=20,76)$,

$\begin{array}{lllll}* .89, & 19, .11, & 23, .20, & 0, \\ 1.65, & 20, .35, & 24, .02, & 0, \\ 2.23, & 16, .77, & 20, .03, & 0, \\ 3.39, & 18, .61, & 21, .00, & 0, \\ 4.16, & 19, .84, & 23, .07, & 0, \\ 5.40, & 36, .67, & 38, .100, & 0, \\ 6.14, & 46, .86, & 47, .00, & 0,\end{array}$

DATA (NDX(1), [ = 1,19?),

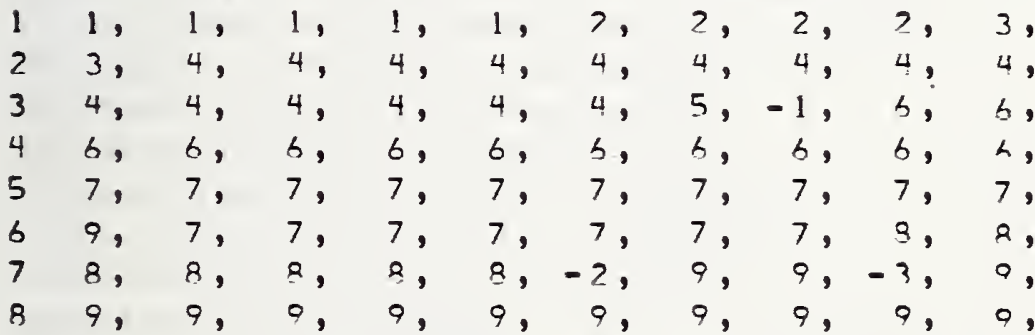
- 14, 14, 14, 14, 14, 14, 14, -6, $-7,14$, ! 14, 14, 14,14,14, $-8,14,14,14,14$, $214,14,-9,14,15,15,15,15,15,15$, $315,15,15,-10,15,15,15,15,15,15$, $416,16,16,16,-11,16,16,16,16,16$, $516,16,16,16,16,16,16,16,13,13$, $613,13,13,13,13,13,13,13,13,13$, $713,13,13,13,13,13,13,17,17,17$, $817,17,17,17,17,17,17,17,17,17$, $917,25,25,25,25,25,25,25,25,25 /$

DATA (NDX(1), $1=191,380)$ /

- 25, 25, 25, 25, 26, 26, 26, 26, 26,-17, $127,27,27,27,-13,27,28,-14,28,28$, 2 $28,-15,78,28,28,29,29,79,29,29$, $329,29,29,29,29,20,29,29,29,30$, $430,30,3 \pi, 30,30,31,31,31,-16,31$, 
. 
$531,31,31,31,-17,31,31,32,32,32$, $632,32,32,32,32,32,32,32,32,32$,

$733,33,33,33,33,33,33,33,33,33$,

$833,34,34,34,34,35,35,35,35,35$,

$935,35,35,35,35,36,36,36,36,36$,

- $36,-18,36,36,18,-19,18,18,18,18$,

$118,19,-70,19,19,19,19,19,19,19$,

$219,19,19,10,20,20,20,-21,20,2 \pi$,

$320,20,-22,21,21,21,21,-73,27,27$,

$422,22,22,73,23,23,23,23,23,23$,

$523,23,-24,24,24,74,24,74,24,24$,

$624,24,37,37,37,37,37,37,37,37$,

$737,-25,38,38,38,38,38,38,38,38$,

$838,39,38,38,38,38,38,38,38,381$

DATA (NOY (I), I =381,512) /

$938,38,38,39,38,38,38,38,38,38$,

- $38,38,38,38,38,38,38,38,39,48$,

$149,40,4 \Pi, 40,40,39,39,39,39,39$,

$239,38,41,41,41,41,41,41,41,41$,

$342,42,42,42,42,43,43,43,43,45$,

$445,45,45,45,45,45,44,14,44,44$,

$544,44,44,44,44,46,46,46,4 h, 46$,

$646,46,47,47,-26,47,47,47,47,47$,

$747,47,49,49,49,49,49,49,49,49$,

$849,40,49,49,49,49,49,49,49,49$,

$949,49,49,49,48,48,48,48,48,48$,

* $\quad 0,0,0,3,0,0,50,50,50,50$,

$150,50,50,50,50,51,51,51,51,5 ?$,

252,571

$C * * *$

IF (IR(1).EQ.0) GO TO IOO

$\mathrm{CTH}=.9817 *(-12.13 \cdot 0+924 \cdot 3 *(P(3) * .421)$

$C T M=.4961 *(-1216 \cdot 0+924 \cdot 0 * I R(3) * * 421)$

$C T L=.4189 *(-1216.0+924 \cdot 0 * I P(3) * * 421)$

R TH $=1349.5751+3.5187867 ? \operatorname{R}(3)$

$R T M=992 \cdot 43256+3 \cdot 1580756 * I R(3)$

$R T L=768.85476+2.6590300 * I R+31$

CTH $=M I N(H A X(C T H, P T H), 1.17 \cdot R T H)$

CTM $=M I N(* A X(C T M, R T H), 1.17 * R T M)$

$C T L=M I M(M A X(C T L, R T L), 1.17 * R T L)$

$C R H=719 \cdot+2.96+1 R(5)$

$C R M=341 \cdot+1 \cdot 70 * 1 R(5)$

$C R L=21 \cdot 4+1 \cdot 47 * I R(5)$

$C A=10543 \cdot+18.97 * 1 R(7)$

$C W=296 \cdot 5+.644 * \mid P(9)$

$C P C=25.84+.2324 * I R(11)$

$C P R=.4148 \cdot I R(13)$

C** DO COMPUTATIOHS FOR HIGH VALUF, LARGE AMD SMAIL.

$D O L=(I R(23)+I R(22)) * C F H+(I P(15)+I R(16)) * C T H+I D(3 C) * C H+I R(29) * C A$

$V O L=I R(23)+I R(22)+I R(15)+I R(16)+I R(30)+I R(29)$

CALL $A D D(1)$

C*** DO COMPUTATIONS FOR MER VALUE,LARGF ANM SMALL.

$D O L=(I R(24)+I R(? 5)) \cdot(R M+(I R(17)+I R(18)) * C T M+I R(31) * C M$

$V O L=I R(24)+I R(25)+I R(17)+I R(18)+I R(31)$

CALL ADD(2)

C... DO COUPUTATIOHS FOR LDY VALUE, LAPGE ANR SNALL.

$D O L=(I R(2 t)+I R(27)) \cdot C R L+(I R(10)+I P(2 Q)) \cdot C T L+I D(32) \cdot C ! !$

$V O L=I R(26)+I R(27)+I R(19)+I R(2 n)+I R(32)$ 



\section{CALL AND(3)}

C... DO COMPUTATIOHS FOR CRUDE.

$D O L=I R(33)+C \cdot+I R(35) \cdot C P C$

$V O L=I R(33)+I R(35)$

CALL $A D \Gamma(4)$

C** DO COMPIITATIONS FOR PEEIHED.

$D O L=1 R(28) \cdot C R L+1 R(21) * C T L+I R(34) \cdot C ":+I R(36) * C P R$

$V O L=I R(2 R)+I R(21)+I R(34)+I R(36)$

CALL $A \cap D(5)$

GO TO $20 \mathrm{C}$

100 DO $110 \quad K=1,5$

$D D \quad 11 C \quad J=1,52$

DO $110 \quad 1=1,52$

$\operatorname{VOLS}(53,53, K)=V \cap L S(53,53, K)+V \cap L S(1, J, K)$

VOLS $(I, 53, K)=V O L S(1,53, K)+V O L S(I, J, K)$

$\operatorname{VOLS}(53, J, K)=V O L S(53, J, K)+V O L \subseteq(1, J, K)$

$\operatorname{DOLS}(53,53, K)=D \cap L S(53,53, K)+D \cap L S(1, J, K)$

DCLS $(1,53, K)=n O L S(1,53, K)+D O L S(1, J, K)$

110 DOLS $(53, J, K)=$ OLL $(53, J, K)+$ OOLS $(1, J, K)$

200 RETURN

C* * SURROUTINF TO IMTERDRET SUBSCPIPTS AND nO tHE AGEREgATIOH. SUBROUTINIE ADR (AK)

IMPLICIT INTEGER (A)

$A I=I R(1)$

$A I=N D \times(A I)$

$A J=I R(2)$

$A J=N D \times(A J)$

IF (AI) $30,900,10$

10 IF (AJ) hO,900,20

C** aGgRegate fop Case nf no sMSa.s.

$20 \operatorname{VOLS}(A 1, A J, A K)=V O L S(A I, A J, A K)+V O L$

$D O L S(A I, A J, A K)=D O L S(A I, A J, A K)+D O L$

GO TO 999

30 IF (AJ) $80,900,40$

c* aggregate for case of trg an smsa.

40 DO $50 \quad A 1=1,3$

$A Z=N P C C^{\top}(-A I, A !)$

IF $(A 2, E O . \cap)$ CO TO 999

VOLS $(A Z, A J, A K)=V O L S(A), A J, A K)+D C T(-A I, A 1) * V O L$

50 DOLS (A2, AJ,AK) = DOLS (A2,AJ,AK)+PCT $(-A I, A 1) * \cap O L$

GO TO 999

C** aggREgate for case cF nest an SMSA.

GO DO $70 \quad A 1=1,3$

$A Z=H P C T(-A J, A 1)$

IF $(A 2 . F \cap . C)$ GO TO 999

$\operatorname{VOLS}(A 1, A 2, A K)=V O L S(A 1, A 2, A K)+P C T(-A J, A 1) * V O L$

$7 \cap D O L S(A I, A 2, A K)=D O L S(A I, A), A K)+P C T(-A J, A 1)=D \cap L$

GO TO 999

C** aggRegate for case of roth opg and dFSt an sisa.

SO DO 9 O $A 1=1,3$

$A Z=N F C T(-A 1, A 1)$

IF $(A 2, E Q . \cap) G O$ TO 900

DO $90 \quad A 3=1,3$

$A 4=N P C T(-A J, A 3)$

IF (A4.EO.D) TOO TO OD

VOLS $(A), A 4, A K)=V \cap L S(A), A 4, A K)+P(T(-A), A 1) \cdot D C T(-A J, A 3) * V \cap L$

$90 D O L S(A 2, A 4, A K)=D \cap L S(A 2, A 4, A K)+P(T(-A I, A I) * P(T(-A J, A 3) \cdot D O L$

GO TO 999 
900 WRITE 6,1$)$ A I, AJ, AK, IR

I FORMATI' ERROR** "/(10110))

१९9 RETURN

END

END DNSITE PRINTOUT ON OCTOBER 6, 1975 AT 13:48:57 $B E A * S U B(1)$. STAG (5) 
APPENDIX I: LISTING OF THE

BAG PROGRAMS 
. 


\section{LISTING OF CONTROL STREAM FOR A RUN OF BAG}

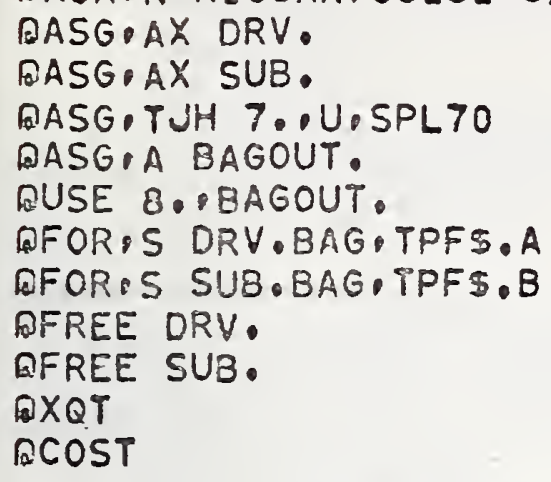



PARAMETER MIR $=37, M B=175, M B 1=M B-1$

INTEGER $C$

DIMENSION IR (MIR.100)

DIMENSION B(MB,MB)

C*** LOOP TO PROCESS ALL 16 MATRICES.

DO 300 MAT $=1.16$

$C=0$

C*** READ A BLOCK FROM THE INPUT TAPE.

10 CALL NTRAN $(7,2, M I R * 100, I R(1,1), L, 22)$

IF $(L . L T .0)$ GO TO 80

C**** BEGIN LOOP TO PASS OF EACH LOGICAL RECORD TO SUBROUTINE. DO $50 \mathrm{~J}=1 \cdot 100$

IF $(I R(1, J), E Q, 0) \quad G 0$ TO 100

$C=C+1$

50 CALL BAG(IR $(1, J), M A T, B)$

GO TO 10

80 WRITE $(6,2)$ L.C

2 FORMAT( * * ERROR L='I5, $C=1$ I5)

C**** COMPUTE ROW AN COLUMN SUMS.

100. DO $110 \quad I=1, M B 1$

DO $110 \mathrm{~J}=1, M B 1$

$B(I, M B)=B(I, M B)+B(I, J)$

$110 B(M B, J)=B(M B, J)+B(I, J)$

$B(M B, M B)=0.0$

DO $120 \quad I=1 . M B 1$

$120 B(M B, M B)=B(M B, M B)+B(I, M B)$

C**** REWIND THE INPUT TAPE AND WRITE OUT THE MATRIX.

CALL NTRAN $(7,10)$

CALL NTRAN $(8,1 \cdot 30625 \cdot B \cdot M \cdot 22)$

WRITE $(6,3)$ MAT

WRITE $(6,1) \quad(B(I, M B), I=1, M B)$

WRITE $(6,4)$ MAT

WRITE $(6,1) \quad(B(M B, J), J=1, M B)$

C**** ZERO OUT THE MATRIX FOR THE NEXT PASS.

DO $200 \quad I=1, M B$

DO $200 \quad J=1 \cdot M B$

$200 B(I, J)=0.0$

1 FORMAT (10E13.7)

3 FORMAT (/ ROW SUMS FOR MATRIX NUMBER'I3/)

4 FORMAT $/ /$ COL SUMS FOR MATRIX NUMBER'I3/)

300 CONTINUE

END 
. 
SURROUTINF BAG(IR, M, PMTX)

DIMENSION IR(37), PCT (1913), IFCT 1913$)$

DI MENSION IIDX(512), Q RHTX(175,175)

EQUIVALFNCF (PCT, IPCT)

DATA $(N D \times(1), 1=1,40) /$

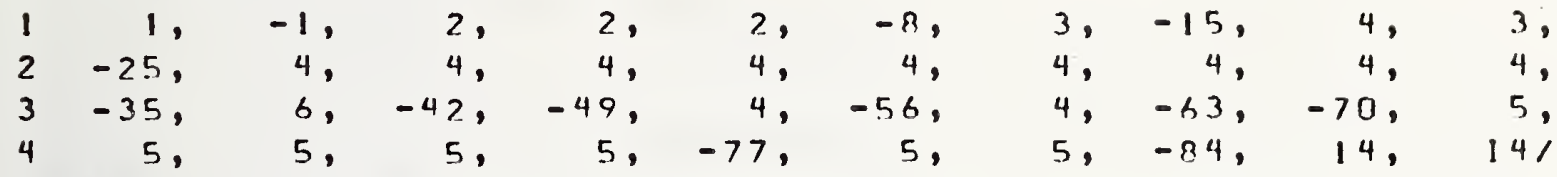

DATA $(N D \times(1), 1=41,239) /$

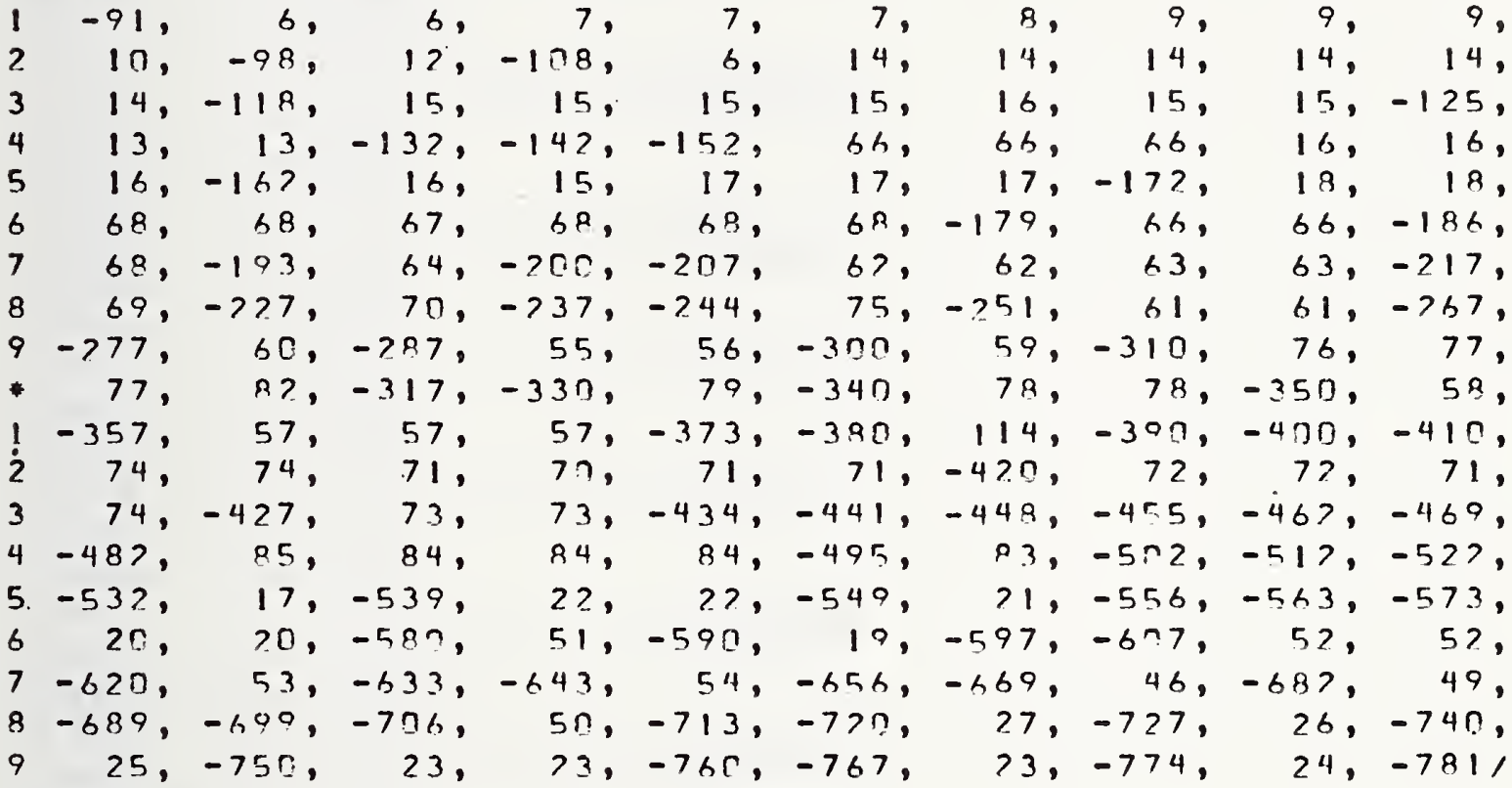

DATA (NDY (1), 1 $=231,42 \pi)$ )

$1-791,-799, \quad 29,-811, \quad 28,-877, \quad 44,-8.34, \quad 32,-944$, $2 \quad 33,-857, \quad 42,-870, \quad 43, \quad 41,-095, \quad 38,-987, \quad 34$, $3-894, \quad 35, \quad 37,-904,-914, \quad 36, \quad 36, \quad 36,-921, \quad 39$, $4-928, \quad 137,-938, \quad 42,-951, \quad 45,-45,-964, \quad 47, \quad 45$, $5-971,-981,-994, \quad 135,-1007, \quad 138,-1023, \quad 138,-1030,139$, $6 \quad 130,-1740, \quad 133,-1047, \quad 132,-1054,-1761, \quad 117, \quad 117,-1074$, 7-1081, $\quad 118,-1088,-1101, \quad 87, \quad 87,-1109,-11 ? 1,-1131,91$, $8-1139,-1148, \quad 103,-1161,-1168, \quad 105, \quad 81,-1178,-1191, \quad 89$, $9-1204,-1214, \quad 106,-1227,-1734,111,111,111,-1244,116$, $-1257,-1264, \quad 114, \quad 93,-1774,-1287,-1794, \quad 67, \quad 107,-1301$, $1 \quad 100,-1311,99, \quad 101,102,-1321,-1328,-1338,102,-1345$, $2 \quad 108,-1355,107, \quad 109,-1362, \quad 111,-1.372,110,-138 ?, 110$, 3-1389, $109, \quad 119,-1396,-1433,-1410, \quad 127,-1432, \quad 121,-1439$, $4122, \quad 131,-1446,-1456, \quad 135, \quad 140,141,-1446,-1485, \quad 143$, 5-1498, 144, 144, 143,-1505, 142, 129,-1517, 128, 127, $6 \quad 127, \quad 127,-1522,-1529, \quad 121,-1551,122,172, \quad 122,-1564$, $7 \quad 123,-1571, \quad 125,124,124,-1590,126,-1670,127,162$, $8-1607, \quad 163, \quad 167, \quad 167, \quad 162,-1614,-1621,-1623,-1635, \quad 146$, $9 \quad 145, \quad 141,-1645,-1657, \quad 94,-1659,-1666, \quad 05, \quad 95,-16791$ DATA $(N \cap \times(1), 1=421,512)$,

$1-1686,-1693,-1793,-1716,-1729,-1736,-1743,-1750,-1757, \quad 151$, $2 \quad 151, \quad 151, \quad 151, \quad 151,-1767,-1774, \quad 149,-1754, \quad 148, \quad 148$, $3-1797, \quad 147, \quad 147,-1804, \quad 149,-1811,154,-1818,-1825, \quad 155$, $4-1835, \quad 155, \quad 157, \quad 157, \quad 157,-1847, \quad 156,187, \quad 158, \quad 158$, $5 \quad 158, \quad 157,-1849,-1856,-1863,169,171,1 \% 1,167,-1873$, 6-1886, 171, 171, 166,-1893, 166,-1900, 135, 165, 165, $7 \quad 165,165,164,165,161,161,160,160,160,-1.907$, $8 \quad 0, \quad 0, \quad 0, \quad 0, \quad 0, \quad 6, \quad 172,1 \% 2,172,172$, 

LISTING OF SURROUTINE PAG

$9 \quad 172, \quad 172, \quad 172, \quad 17 ?, \quad 172, \quad 173, \quad 173,173,173, \quad 174$,

- $174,174 /$

DATA (PCTII), I= 1, 7)/002002,

1.0792,.Ch?.6, D?1,

$2.9204, .9374,0021$

DATA (PCTI), I =

1.2723,.3296,032,

$2.7277, .6774,0: 4 /$

DATA IPCTII), I =

$15,241 / 1008503$

1.0935,.0755, 0n3,

8, 141/006002,

2. $1845, .1641, \mathrm{CC} 5$,

$3.7220, .7604,004 /$

DATA (PCTII), I = 25, 34)/011003,

$1.1900, .1700,006$,

$2.6100, .5900,003$,

$3.2000, .24 \cap 0,025 /$

DATA (PCT(I), I = 35, 41)/[21002,

$1.5669, .5410,0 \cap 5$,

$2.4331, .4590,004 /$

DATA (FCT (I), I =

1.8078,..8774, 006 ,

$2.1922, .1726,005$,

DATA (PCTI I), I = 49, 55)/1024חE),

$1.0071, .0: 70,024$,

$2.9929, .9930,005 /$

DATA IPCT(1), $1=$

1.031r, ,.033C,005,

$2.9690, .9670,0041$

DATA (PCT (I), $1=$

1.8984,.8879,084,

$2.1016, .1371,005$,

DATA (PCT(1), I = 70, 76)/02900?,

1.2836,. 3659,004 ,

$2.7164, .6391,0 \cap 51$

DATA (PCT11), ) =

1.4966,.5057,005,

$2.5 \cap 34, .4943,0141$

DATA (PCTI1), I =

1.1034,.1245,005,

2.896h,.88755,014/

DATA (PCT (1), I =

$42, \quad 481 / 023 \cap 02$,

56, 421/026002,

$63,691 / 028502$,

$77,831 / 035002$,

1.8537; .8823,026,

7. $1463, .1177,0671$

DATA (PCT (I), I = $98,107 / / 052003$,

1.3012,.3239,037,

$2.4251, .4648,01$ ?,

$3.2737, .2342,0081$

DATA (DCT(I), I = 108, 117$) / 054003$, $1.6756, .6715,012$,

$2.2195, .2313,007$,

$3.1049, .0972,0561$

DATA (PCT(1), I = 118,124$) / 062 \pi 02$,

$1.8770, .9156,014$,

2. $1230, \therefore 0244,0151$

DATA (PCT(1), I = 125,131$) / 070002$,

$1.7241, .7453,015$,

$2.2759, .2547 .0131$

DATA (PCTII), I = 132,141$) / 073003$, 

$1.3590, .3320,012$

$2.5308, .5801,011$,

$3.080 ?, .0079,0131$

DATA (PCTII), I = 142, 151)/074003,

$1.6628, .6866,011$,

$2.1651, .1579,046$,

$3.1721, .1556,0091$

DATA $(P C T(1), 1=152,161) / 075003$,

1.3399,..3251,066,

$2.2970, .3009,010$,

$3.3631, .3740,0671$

DATA (PCTII), I = $162,1711 / 082003$, 1.1061,.1171,013, $2.5700, .5903,016$, $3.3239, .2926,015 /$

DATA (PCTI), I = 172,178$) / 08800 ?$, $1.3178, .3570,066$,

$2.682 ?, .6421,0171$

DATA (PCT (1), 1 = 179, 185)1097002, $1.9659, .9543,068$,

$2.0341, .0457,066 /$

DATA (PCTI), I = 186, $1921 / 100002$, 1.3757,.3953,048,

$2.6243, .6047,070 /$

DATA $(P C T(1), I=193,199) / 102302$, $1.9623, .9275,034$, $2.0377, .0725,066 /$

DATA $(P C T(I), 1=200,236) / 104002$, $1.8229, .8524,064$,

2.1771,.1476, D5?

DATA $(P C T(1), 1=227, ? 16) / 105003$, 1.3910,.3718,062,

$2.3544, .3676,264$,

$3.2543, .2606,0521$

DATA (PCT $111, I=217,276) / 110003$, 1.265ח,.2815,049,

$2.5555, .5515,063$,

$3.1796, .1670,364 /$

DATA $(P C T(I), I=227,236) / 112703$, 1.4940,. 4595,068,

$2.1478, .1242,060$,

$3.3583, .4164,0364 /$

DATA (PCT(I), I= 237, 2431/114302, $1.5782, .5992,075$,

$2.4218, .4008,0701$

DATA (PCTI I), I = 244, 250)/115002, 1.3281,. 2560,075 ,

$2.6719, .7440,076 /$

DATA (PCT(1), I = 251, 266)/117005, $1.2422, .216 \Pi, 075$,

$2.2397, .2562,061$,

3. $0948, .0710,059$,

$4.3897, .47 .69,060$,

$5.0341, .0330,0761$

DATA (FCTII), I = 267, 276)/120ח03, 1.2026,.1934, G6?,

2.7171,.741R, C61,

$3.0803, .0650,060 /$ 

DATA (PCT(1), 1 = 277, 286)/121303,

$1.7184, .7638,0 \leq 0$,

$2.1826, .1608,254$,

$3.099 C, .0754,0621$

DATA (PCTI (1), I = 287, 290)/123504,

1.1286,.0051,054,

$2.6389, .7192,055$,

$3.0758, .0541,056$,

$4.1567, .1316,0601$

DATA (PCTI), I = 300, 309)/126003,

$1.6249, .6557,059$,

$2.1313, .0973,056$,

$3.2438, .2470,0601$

DATA (PCT (I), I = 310, 316)/128002,

1.1575,.1435,059,

$2.8425, .8505,077 /$

DATA $(P C T(1), I=317,320) / 133004$,

$1.2763, .2882,079$,

$2.2276, .2250,077$,

$3.0634, .5485,091$,

$4.4327, .4383,0821$

DATA (PCTII), I = 330, 339)/134003,

1.1502,.1236,079,

$2.7717, .2199,077$,

$3.0781, .5565,0781$

DATA (PCT(I), I = 340, 349)/136703,

$1.7459, .8027,078$,

$2.1783, .1434,113$,

$3.0758, .054 \pi, 0.791$

DATA $(P C T(1), I=350,356) / 139002$,

$1.3912, .4189,058$,

$2.6089, .5811,0771$

DATA (PCT(1), I = 357, 372)/141?05,

1.1243,.1277,056,

$2.2463, .2508,114$,

$3.3888, .4044,052$,

$4.1215, .1232,055$,

$5.1190, .0859,0571$

DATA (PCT(I), I=373, 379)/14500), $1.8455, .8455,114$,

$2.1545, .1545,557 /$

DATA (DCT(I), I = 390, 389)/146003,

1.1769,.1755,115,

$2.6528, .6653,114$,

$3.1703, .1503,0551$

DATA $(D C T(1), 1=390,399) / 142003$,

$1.5059, .5415,113$,

$2.1849, .1255,114$,

$3.3092, .3330,0571$

DATA (PCT(I), I = 400, 400)/140003,

1.1646,.1323,073,

$2.2308, .1904,074$,

$3.6046, .6776,0761$

DATA (PCT(1), I = 410, 419)/1577C3,

$1.6199, .6233,074$,

$2.2432, .2454,07 n$,

$3.137 n, .1313,0761$

DATA (OCT (I), I = 420, 4>6)/15770), 

DATA (PCT(1), I= 563, 572)/189503,

1.6910,.749ח,019,

$2.2033, .1409,018$,

$3.1057, .0911,0211$

DATA (PCT(I), I = 573, 579)/190nO?,

$1.3843, .3130,020$,

$2.6157, .6970,0191$

DATA (PCT(I), I = 580, 580)/193003, 1.0148,. त104, C51,

$2.1379, .1069,025$,

$3.8473, .8229,0701$

DATA (PCT (I), I =590, 506)/19500?, $1.7292, .7592,052$,

$2.2709, .2909,0511$

DATA $(P C T(1), 1=597,6 C 6) / 197003$,

$1.8136, .8369,255$,

$2.1264, .1171,052$,

$3.0602, .0461,066 /$

DATA (PCT (1), ! = 607, 619)/198004,

$1.3715, .3719,252$,

$2.0173, .71 ? 0,065$,

$.3 .4872, .5379,064$,

$4.1>20, .0773,06 \mathrm{~B} /$

DATA $10(T(1), 1=620,6321 / 201004$,

$1.5070, .5463,753$,

$2.1919, .1899,062$,

$3.1825, .1618,352$,

4.1186,.1719,10541

DATA (PCT(I), I=633, 542)/203903, 1.4n32,. 3925,050,

$2.2970, .2956,053$,

$3.2999, .3159,0521$

OATA (DCTII), I = 443,655$) / 204004$,

$1.4124, .3817,053$,

$2.1744, .1233,249$,

$3.4367, .4747,254$,

4. $0766, .0203,050 /$

DATA (PCT(I), ! =656, 668)/2056504,

1.2390,.2749,115,

$2.0606, .0374,554$,

$3.2695, .3191,049$,

$4.3813, .3626,0551$

DATA (OCT(1), 1 = 669, 691)1207:04, $1.0771, .0136,049$,

$2.8131, .8176,044$,

$3.0649, .0577,047$,

4.0950,.17?0,115/

DATA $(O C T(1), 1=682,428) / 279 C 02$,

1.89ח6,. $95.24,049$,

2.1094,.007h, 0471

DATA (FCT(I), I=689, 698)/211003,

$1.1711, .1256,049$,

$2.6332, .6808,049$,

$3.1957, .1936,3531$

DATA $(P C T(1), 1=699,705) / 21>\pi n 2$,

$1.9823, .9978,948$,

$2.0177, .01 ? 2,044 /$

DATA (PCT(1), $1=706,712) / 2135002$, 
$1.6317, .6670,048$,

$2.3983, .3330,050 /$

DATA (PCTII), I = 713, 719)/215002,

$1.2814, .2501,550$,

$2.7186, .7499,0511$

DATA $(P C T(1), 1=720,726) 1716002$,

$1.0687, .0788,348$,

$2.9313, .9212,027$,

DATA $(P C T(I), I=727,739) / 218004$,

$1.7764, .7916,026$,

$2.1419, .1415,025$,

$3.0653, .0579,027$,

$4.0165, .0090,0281$

DATA (PCT(I), I = 740, 749)/220003, $1.5123, .5437,026$,

2.1849,.1861,023,

$3.3023, .27 \cap 8,025 /$

DATA (DCT(I), I = 750, 759)/222nח3,

1.6223,.66360,025,

$2.0435, .0307,0>0$,

$3.3 .342, .3332,023 /$

DATA $(P(T(1), I=760,766) / 225002$,

1.8259,.88425,023,

$2.1741, .1575,0221$

DATA (PCTII), I= 767, 773$) / 22600 ?$,

1.7255,.7402,024,

$2.2745, .2592,0231$

DATA (DCT(1), $1=774,780) / 229002$,

1.6884,.663?,023,

$2.3116, .3368,0241$

DATA $(P C T(1), I=781,790) / 230003$,

1.6552,.6559,03C,

$2.2632, .2631,029$,

$3.0817, .0811,0261$

DATA $(P C T(I), I=791,797) / 231002$,

$1.5707, .4759,031$,

$2.4293, .5741,0281$

DATA (PCT (I), I = 708, $8101 / 232004$,

1.1464,.1526,032,

$2.5426, .5355,031$,

$3.2759, .2873,029$,

$4.0351,0245,0331$

DATA (PCT(I), I = 811, 826)/234305,

$1.5139, .5396,028$,

$2.2932, .3234,031$,

$3.1232, .1002,026$,

$4.0319, .0226,032$,

$5.0478, .0362,0291$

DATA (PCTI), I = 227,933$) / 233002$,

$1.7615, .7365,044$,

$2.2385, .2635,048 /$

DATA (PCT (I), I = 834, Q43)/238003,

$1.2169, .2310,042$,

$2.6365, .6527,044$,

$3.1466, .1704,0321$

DATA (PCT(1), I = 844, 856)/740074,

$1.5959, .6514,033$,

$2.2034, .2708,032$, 
$3.1781, .1832,042$,

$4.0226, .0146,2341$

DATA $(P C T(1), I=857,869) / 242004$,

1.0932,.0090,033,

$2.4545, .4611,041$,

$3.1705, .1449,042$,

$4.2818, .2950,234 /$

DATA (PCT(1), $1=870,879) / 244003$,

$1.5412, .5120,044$,

$2.1627, .1654,042$,

$3.2961, .3226,0431$

DATA (PCT(1), I = 8BO, 886)/247n02,

$1.8041, .7997,041$,

$2.1959, .2[03,043 /$

DATA (PCTII), I = 887, 803)/249002,

1.7427,..7600,034,

$2.2573, .2450,0381$

DATA (PCT (I), I = 894, 903)/251nO3,

$1.4188, .487 \mathrm{~h}, 034$,

$2.1601, .1077,037$,

$3.4 \geq 11, .4047,[351$

DATA $(P C T(1), 1=904,9131 / 254003$,

$1.2752, .3379,035$,

$2.5391, .5370,537$,

$3.1357, .1251,0361$

DATA $(P(T(I), I=914,920) / 2550 C 2$,

$1.7003, .64 \pi 6,037$,

$2.2997, .3504,0361$

OATA (PCT(1), I = 021, 927)/259002,

1.6203,.6060,038,

$2.3797, .3940,0391$

DATA (PCT(I), $1=928,9271 / 261503$,

1.8826,..8094,340,

$2.0311, .0258,137$,

$3.0962, .0748,0391$

DATA (PCTII), I = 938, $9501 / 263004$,

1.3909,. 3?88,040,

$2.1987, .1468,045$,

$3.1658, .1810,136$,

$4.2446, .2834,1371$

DATA (PCT(I), I = 951, 963)/2650?4,

1.5374,.549?, 045 ,

$2.2805, .2779,043$,

$3.0261, .2174,044$,

$4.1560, .1555,0401$

DATA $(D C T(1), 1=964,970) / 769002$,

1.3637,. 319ח, 345 ,

$2.6363, .6810,0471$

DATA (PCT(I), I = 971, 900)/271C03,

$1.1035, .0779,045$,

$2.5286, .5625,048$,

$3.3679, .3506,0471$

DATA (PCTII), I = 981, 9931/27>0.04,

1. तर5 ,. ח924,047,

$2.4196, .3850,046$,

$3.4397, .4718,045$,

$4.0548, .0499,134 /$

DATA (PCTII), I = 994,1906)/773004, 
$1.2660, .2501,135$,

$2.3845, .3963,134$,

$3.1431, .1572,045$,

$4.2064, .2733,1361$

DATA $(P C T(1), I=1007,1022) / 775005$,

$1.2811, .2439,138$,

$2.079 C, .0691,135$,

$3.2441, .23 ? 1,136$,

$4.3810, .4217,137$,

$5.0148, .0131,1341$

DATA (PCT(I), I =1023, 1020$) / 277002$,

1.7769,. 7596,138 ,

$2.2231, .2404,1391$

DATA (PCT(I), I =1030,1039)/779003,

$1.6432, .6411,139$,

$2.3071, .3100,133$,

$3.0496, .0489,138 /$

DATA $(P C T(1), 1=1040,1046) / 282002$,

1.8642,..9ก55,133,

$2.1358, .0945,1381$

DATA (PCT(1), $1=1047,1053) / 284002$,

$1.6236, .6481,132$,

$2.3764, .3519,133 /$

DATA (PCT (1), $1=1054,1062) / 286002$,

$1.8977, .9165,134$,

$2.1023, .0835,1171$

DATA $(P C T(1), 1=1061,1073) / 287004$,

1.1034,.0994,046,

$2.3310, .3450,134$,

$3.2050, .1377,117$,

4.3606,..3678,1311

DATA (PCT(1), $1=1074,1980) / 293002$,

$1.572 n, .5452,117$,

$2.4280, .4548,546 /$

DATA (PCT(I), I = 1081,1097)/291002,

$1.3174, .2898,117$,

$2.6826, .7102,0461$

DATA $(P C T(1), 1=1088,11 G C) / 293004$,

$1.2702, .2 ? 05,116$,

$2.6157, .6711,119$,

$3.0418, .0383,118$,

4.0723,.0510,1171

DATA $(P C T(1), 1=1101,1107) / 794002$,

1.7598,. 7525,117 ,

$2.2402, .2475,1181$

DATA (PCT(I), I $=1198,1123) / 297004$,

1.1755,.1644,007,

2.1385, 1 1246, त91,

3. $4358, .4506,092$,

4.25ह2,. 26त3, 0271

DATA $(P C T(1), 1=1121,1130) / 298$ R. 3,

1.823B,. $8 \cap R 7,091$,

?. $0636, .0772,087$,

$3.1127, .1191,0071$

DATA (PCT(I), I =1131,1137)/299502,

1.6732, . h694,091,

$2.3268, .3356,0991$

DATA $(P C T(I), I=1138,1147) / 301$ O 
$1.5230, .4867,091$,

$2.3873, .4271,790$,

$3.0396, .0862,0291$

DATA (PCT (I), I =1148,1160)/377004,

$1.43 C 3, .4698,104$,

$2.3477, .3430,133$,

$3.1070, .1008,175$,

$4.0919, .02864,0001$

DATA (PCT(1), I =1161,1167)/304002,

$1.8878, .8921,195$,

$2.1122, .1379,1341$

DATA (PCT(I), I =1168,1177)/305003,

$1.4157, .4234,031$,

$2.4865, .4670,105$,

$3.0979, .1996,1031$

DATA (DCT(I), I $=1178,1100) / 308004$,

1.1643,.1593,107,

$2.2276, .1902,106$,

$3.5241, .5578,174$,

$4.0840, .0837,1031$

DATA $(D C T(1), I=1101,1203) / 300004$,

$1.1406, .1331,050$,

$2.1385, .1203,135$,

$3.0699, .5685,1.54$,

$4.6510, .6602,1031$

DATA $(P C T(1), 1=1274,1213) / 311203$,

1.5674,.5728, 080,

$2.3776, .3419,079$,

$3.1051, .085 ?, 0811$

DATA $(P C T(1), 1=1214,1226) / 31>504$,

$1.5164, .4577,106$,

$2.2969, .3537,113$,

$3.1356, .1335,079$,

$4.0511, .0451,0801$

DATA (PCT (1), I =1227,12331/314002,

1.371?,..3543,176,

$2.6 ? 88, .6457,1071$

DATA (PCT(I), $1=1234,1243) / 315003$,

$1.7058, .7286,112$,

$2.1396, .1133,113$,

$3.1546, .1581,1141$

DATA (DCTII), I $=1244,(256) / 310 \mathrm{CO}$,

1.3551,.3 358,111 ,

$2.2626, .2722,112$,

$3.1161, .0934,116$,

$4.2661, .3224,1141$

DATA (PCT(I), I $=1257,1263) / 321002$,

$1.9467, .9564,116$,

$2.0533, .0436,1141$

DATA (DCT (1), ! = 1 264,1273)/322r03,

$1.6411, .6753,115$,

$2.3307, .3704,114$,

$3.0282, .0243,1161$

DATA (PCT(I), $1=1774,1286) / 325004$,

1.7409,.7645, 09?,

$2.1335, .1201,097$,

$3.0735, .0673,093$,

$4.0521, .0420,0961$ 

DATA (PCT(1), I = $1287,12931 / 326002$,

$1.9417, .9473,096$,

$2.0583, .0527,0931$

DATA $(P C T(1), 1=1294,1300) / 327 r 02$,

$1.6133, .58>4,097$,

$2.3867, .4176,0961$

DATA $(P C T(1), 1=1301,1310) / 330003$,

1.3122,.3172,099,

$2.5388, .5320,098$,

$3.1490, .1528,100 /$

DATA (PCT(1), I =1311,13201/332003,

$1.4385, .4240,399$,

$2.5087, .5182,173$;

$3.0528, .0578,1 \cap 0 /$

DATA (FCTII), I =1321,1327)/336002,

1.1721,.1654,102,

$2.8279, .8346,1331$

DATA (PCT(1), I $=1328,1337) / 337003$,

$1.4549, .4486,103$,

$2.0530, .0404,1: 2$,

$3.4921, .552 n, 1071$

DATA (PCT(I), I =1338,1344)/338002,

$1.8619, .8723,122$,

$2.1381, .1777,1481$

DATA (PCT(I), I $=1345,1354) / 340003$,

$1.5976, .5906,108$,

$2.2855, .3140,107$,

$3.1168, .0954,1571$

DATA (PCT(I), $1=1355,1361) / 34200 ?$,

$1.1959, .1455,107$,

$2.8041, .8545,1081$

DATA (PCT(1), I =1362,1371)/3450103,

$1.8315, .8529,111$,

$2.0549, .0488,110$,

$3.1136, .0093,1391$

DATA (PCTII), 1 =1372,1391)/347003,

1.5221,.5475,116,

$2.4313, .4132,111$,

$3.0465, .0394,1101$

DATA $(P C T(1), 1=1382,1388) / 349 \pi 02$,

$1.7259, .7196,110$,

$2.274 i, .2814,1091$

DATA (PCT(1), I =1389,1395)/351r.02,

1.8317,. 9326,109 ,

$2.1683, .1674,1101$

DATA (PCT(1), $1=1396,1402) / 354 n 02$,

$1.7997, .7663,119$,

$2.2003, .2337,116 /$

DATA (PCT(1), 1 =1403,1418)/355005,

$1.0345, .0310,120$,

$2.1357,1096,127$,

3.170त,.17r: , 131,

$4.1051, .1506,119$,

$5.5547, .5889,1191$

DATA (PCT(1), I =1419,1431)/356004,

$1.7107, .6925,120$,

$2.1698, .173 .1,121$,

$3.0204, .0173,127$, 

4.0996,.1272,118/

DATA (PCT (I), $1=1432,1438) / 358702$,

I. $4488, .4311,120$,

$2.5512, .5689,1211$

DATA (PCT (1), I=1439,1445)/360002,

$1.6168, .6045,170$,

$2.3832, .3955,119 /$

DATA $(D C T(1), 1=1446,1455) / 363003$,

1.2728,.2.645,131,

$2.2576, .2465,127$,

$3.4697, .4900,13 \mathrm{Cl}$

DATA $(P C T(1), I=1456,1465) / 364003$,

$1.7369, .7631,13 \mathrm{C}$,

$2.1345, .1121,140$,

3.1286,.1240,141\%

DATA (PCT (1), $1=1466,1484) / 368006$, 1. $0231, .9257,124$,

2.0865,.0687, 141 ,

$3.4206, .5076,128$,

$4.3187,2861,129$,

$5.0445, .0338,130$,

$6.1066, .0772,127 /$

DATA $(P C T(1), I=1485,1497) / 369004$,

1.1231,.1329,143,

2. ก888,. C645,129,

$3.4843, .5065,142$,

$4.3937, .2970,141 /$

DATA (PCT (1), I=1498,15n4)/371ח02,

$1.7959, .7925,143$,

$2.2041, .2075,144 \%$

DATA (OCT (1), $1=1505,1511) / 375902$,

1.8286,.8199,142,

$2.1714, .1901,1431$

DATA (กCT (1), $1=1512,1521) / 378003$,

1.5135,.45.39,14?,

$2.3148, .3333,129$,

$3.1717, .2 \Omega 78,126 /$

DATA $(=C T(1), I=1522,1528) / 383002$,

1.2193,.1733,121,

$2.7807, .8267,127 /$

DATA $(O C T(1), I=1529,1550) / 384207$,

1.1151,.0.857,128,

2.1414,.1304,125,

$3.5373, .6059,145$,

4. $1383, . \cap 235,14$,

$5.1163, .1 \cap 87,127$,

$6.0741, .0220,126$,

$7.0775, . \Gamma 237,121 /$

DATA (PCT(I), I=1551,1533)/386004,

1. $4574, .4177,121$,

2.1153,.1195,172,

$3.357 n, .3974,123$,

$4.7703, .0724,125 /$

DATA (DCT (I), I = 1564,1570$) / 39070 ?$,

1. $755 \mathrm{c}, .7268,123$,

$2.2445, .2732,122 /$

DATA IPCT(1), $1=1571,1589) / 39 ? 706$,

1.1269,.1773,13n, 


\section{.}


$2.4247, .4481,124$, $3.0207, .0182,126$, $4.2557, .2479,175$, $5.0849, .7852,173$, 6.0877,.0927,1221

DATA (PCT(1), $1=1590,1599) / 396003$, $1.5354, .5510,124$, $2.3702, .3640,142$, $3.0944, .8841,126 /$

DATA (PCT(1), I =1600,1656)/398002, $1.2197, .2306,145$,

$2.7803, .7694,174 /$

DATA (PCTI), 1=1607,1613)/40100?, $1.4967, .5001,163$, $2.5033, .4099,16 ? 1$

DATA (PCTII), 1=1614,1620)/406002, $1.7959, .8606,145$,

$2.2041, .1394,1461$

DATA (PCTI I), I=1621,1627)/4n7002, $1.6724, .6798,146$, $2.3276, .3252,1491$

DATA (PCT(1), $1=1628,1634) / 498502$, $1.8276, .8177,146$, .

$2.1724, .1823,1221$

DATA (PCT(1), I =1635,1644)/409ח03, $1.8599, .8339,122$,

$2.0894, .073 ?, 145$, $3.0509, .0431,1461$

DATA (OCT(I), $1=1645,1651) / 413022$, $1.6793, .6738,153$, $2.3707, .3742,094 /$

DATA (FCT(1), $1=1652,1658) / 414002$, 1.7705,.7648,153, $2.2295, .2352,0041$

DATA (PCT(1), I =1659,16h5)/416502, $1.9464, .9532,094$,

$2.0536, .0468,095 /$

DATA (PCT(1), 1=1666,1678)/417004, $1.4664, .4519,0.93$,

$2.2940, .3520,095$, $3.2119, .2107,094$, $4.0277, .0279,0961$

DATA (PCT(1), I=1679, 1685$) / 420002$, $1.121 \mathrm{C}, .1282,004$,

$2.8790, .8718,095 /$

DATA (PCT (1), $1=1686,1692) / 421002$, $1.6337, .5811,154$,

$2.3663, .4109,1521$

DATA (PCT (I), I = 1693,17ח2)/422003, 1.1382,.1449,159,

$2.6367, .6432,152$,

$3.2755, .2170,154 /$

DATA $(P C T(1), 1=1773,1715) / 423004$, $1.6049, .6192,152$,

$2.0478, .0378,151$,

$3.2705, .2963,154$, $4.0768, .0566,159 /$

DATA (PCT (1), I $=1716,1778) / 424004$, 


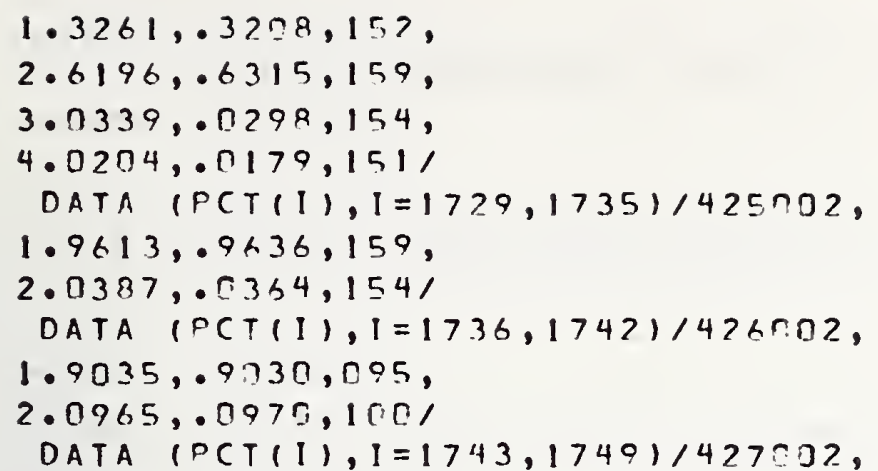

$1.8642, .8554,150$,

$2.1358, .1446,100 \%$

DATA (PCT(I), I $=(750,1756) / 428002$, $1.9456, .9474,150$,

$2.0544, .0576,1 ? 1 /$

DATA (PCT(I), I =1757,1766)/429003, $1.3479, .3543,150$,

$2.5512, .5601,151$,

$3.1309, .0856,1521$

DATA IDCT(I), $1=1767,1773) / 435032$, $1.4720, .4692,161$,

$2.5280, .53 \cap 8,151 /$

DATA (PCT(I), I =1774,1793)/436003, $1.2229, .2223,151$,

$2.2267, .1813,161$,

$3.5504, .50 \times 4,1491$

DATA (PCT(I), $1=1784,1796) / 438004$, 1.0959,.06ก0,147,

$2.7394, .7699,148$,

$3.1576, .1645,149$,

4.0071,.0056,1501

DATA (PCT(1), I $=1797,1903) / 441502$,

$1.7372, .7918,147$,

2.2628,. 2002,149/

DATA (PCT (I), I =18ח4, 181C)/444002,

$1.9635, .9526,147$,

$2.0365, .0474,149$,

DATA (PCT(I), I = 1811,1317$) / 446002$,

1.2406,.2351,154,

$2.7594, .7649,155 /$

DATA (PCT(I), I $=1818,1824) / 448002$,

1.5388,.5ก72,154,

$2.4612, .4928,1561$

DATA (PCT(I), I $=1825,1834) / 449503$,

$1.6649, .6679,156$,

$2.3008, .31739,154$,

$3.0343, .0354,1571$

DATA (PCT(I), I =1935,1841)/451002,

$1.8391, .9148,155$,

$2.1609, .1852,1571$

DATA (PCT(I), I =1842, (848)/456002,

$1.9564, .9559,157$,

$2.0436, .0441,156 /$

DATA (PCT(I), $1=1849,1855) / 463002$,

$1.5363, .539 ?, 170$,

$2.4637, .4698,1691$

DATA $(P C T(1), I=1856,1862) / 464 \pi 0 ?$, 




\section{LISTING OF SUBROUTINE RAG}

$A D=\| M \times(A \cap)$

IF $(A O) 2 \cap 00,6 ? \cap 0,170 n$

1700 IF (AD) $1000,620 \pi, 1800$

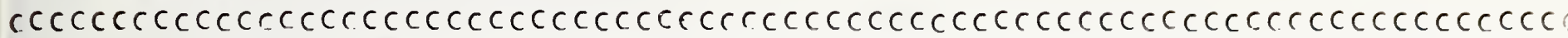
CCCCC IN THF FOLLOWING COMNENT STATEMFNTS THF NOTATION WILL DE: CCCCCCCCCCE CCCCC $O=D R I G I N$ NNS $7 O N E ; \quad D=D E S T I N A T I O N$ NNS TONE CCCCCOCCCCCCCCCCCCCCCCCC

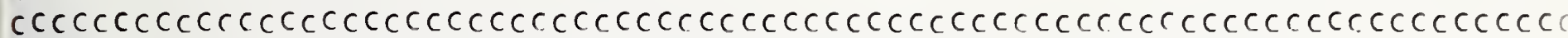

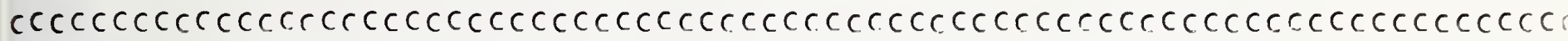
CCCCC AGGREGATF FOR CASE OF ROTH O \& O ENTIRFLY "ITHIN SINGLE REA ZONES CCC CCCCCCCCCCCCCCCCCCCCCCCCCCCCCCCCCCCSCCCCCCCCCCCCCCCCCCCCCCCCCCCCCCCCCCCCC $1800 \quad R M T X(A \cap, A \cap)=B M T \times(A O, A D)+X$

GO TO 9999

CCCCCCCCCCCCCCCCCCCCCCCCCCCCCCCCCCCCCCCCCCCCCCCCCCCOCCCCCCCCCCCCCCCCC CCCCC AGGREGATF FOR CASE OF O IN SINGLE REA TONE AND D IN MIJLTIPLE ZONES CC

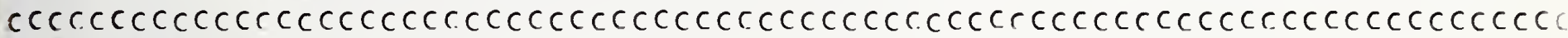
$1900 \quad A 3=I^{\circ} C T(-A D) / 1 \cap 00$

IF $(A 3, N E \cdot I R(2))$ GO TO 6400

$A 4=M O D(I P C T(-A D), 1 C \cap \cap)$

DO $1950 \quad K=1, A 4$

$A D K=1 P C T(3 * K-A D)$

$P C T D K=P C T(3 * K-A D-2)$

$1950 \quad B M T X(A \cap, A D K)=B M T X(A O, A \cap K)+P C T D K * X$

60 TO $\cap 999$

2000 IF $(A D) \quad 2200,6259,2100$

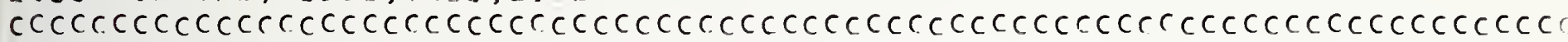
CCCCE AGGREGATF FOR CASE DF O IN MULTIPLE ZONES AND D IN SINGLE REA ZUNE CS

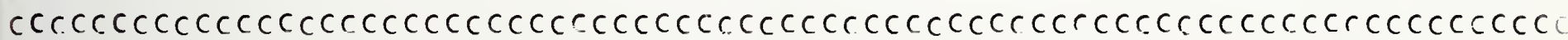
$2100 \quad A 1=I P C T(-A 0) / 1020$

IF (AI.NE.IR(I)) GO TO 6300

$A 2=\operatorname{MON}(I P C T(-10), 1000)$

DO $2150 \quad J=1, A$ ?

$A O J=I F C T(3 * J-A O)$

$P C T O J=P C T(3 * J-A \cap-1)$

2.15O BHTX( $\triangle O J, A D)=R M T X(A O J, A C)+P C T O J * X$

GO TO 9999

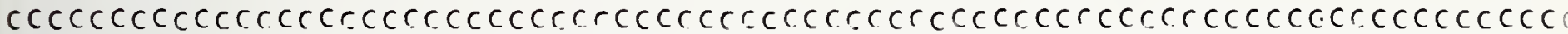
CCCCC AGGREGATE FOR CASE OF ROTH O \&. D IN MULTIDIE REA 7 MIFS CCCCCCCCCCCCCC

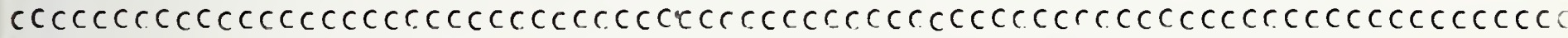

$2203 \quad A 1=1 P C T(-10) / 1000$

$A 3=I P C T(-A \cap) / 1 \cap 00$

IF $(A I . N E \cdot I R(1))$ GO TO 6300

IF $(A 3 \cdot N E \cdot I R(?))$ GO TO 6400

$A 2=M O D(I P C T(-A 0), 10 \cap 0)$

$A 4=M O D(I D C T(-A D, 10 C 0)$

DO $2250 J=1, A 2$

$A O J=I P C T(3 * J-A \cap)$

$P C T O J=P C T(3 * J-A D-1)$

DO $225 \cap K=1, \wedge 4$

$A \cap K=1 P C T(3 * K-\triangle D)$

$P C T \cap K=P C T(3 * K-A \cap-2)$

$2250 \quad A M T X(A \cap J, A \cap K)=R M T \times(A O J, A \cap K)+P(T O J * P C T D K * X$

GO TC 9909

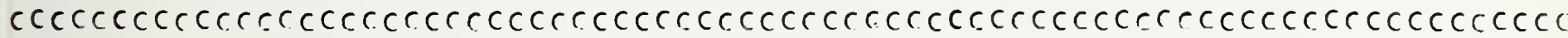
CCCCC THE REMAINDER OF THIS PROGRAM CONSISTS OF FRROR MFSSAFFS CCCCCCCCCCCC

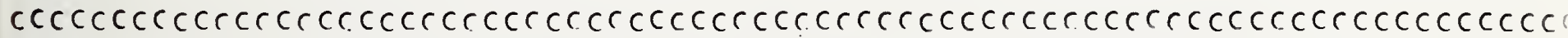
6OD MRITE(h, hOOI) IR(1), IR(2)

6001 FORMATI. FRROF,RAD IHPUT PECORD. UWKNOMN ORIGINE IP(1), IR(2):12

$+(10)$ 


\section{LISTING OF SURROUTINE RAG}

60 TO 9999

6100 MRITF $(6,6101)$ IR(1),IR(2)

6101 FORMATI" ERPOR, RAD INFUT RECORD, UNKNOMN DESTINATION. IRII), IRI $+21: 121101$

GO TO 9999

6200 WRITE $(6,62 \pi 1)$ IR(1),IR(2),AO,AD

6201 FORMATI ERROR, BAD NDX MAPPING.IR(1), IP(2), AO, AD:14I10) GO TO 9999

6300 HRITE(6,6301) IR(1),IF(2),AO,AD,AI, A3

63तI FORMAT( EPPROR, BAD PCT MAPPING (AI-IR(1)), IR(1), IR(2), A , AD,A1, A3: +16 I 101

GO TO 0999

64Cח HRITE (6,6401) ID(1), !R(2), AO, An, AI, A.3

6401 FORMAT('ERROR, RAD PCT MAPPING (A3-IR(2)), IR(1),IR(2),AO, AD,AI, A3: $\left.+\cdot 6 I \mid r_{1}\right)$

GO TO 9999

१९९9 RETURH

END

END ONSITE PRIIITOUT ON OCTORER 6, 1975 AT 13:49:37

$B E A:$ SUB (1). DAG(14) 


\section{$O=\cos 4$ TिAPHIC DATA SHEET

1. ITMRATION OR RHPOK[ IO
NBSTR 75-911 NBSIR 75-911}

1? LE ANU SI:IBTITRE

A National Network Data Base System
2. hov's Acoessiun Nin.

3. liec ipient s .lecension ${ }^{\circ}$.

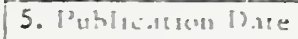

September 1375

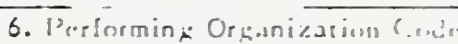

8. Porterming ()agan. Repur: $\because 0$

Richard H.F. Jackson

9. PERFOR MING ORGANIZATION NANE AND ADDRESS

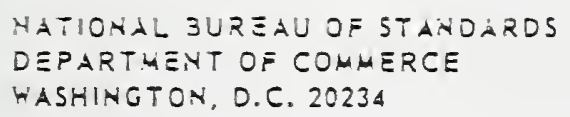

12. Sponsoring Orgunization Nime and Complete Address (Street, City, State, ZIP)

U. S. Department of Transportation

U. S. Departwent of Comerce

U. S. Department of the Army

13. Type of Repurt \& Period Cinvered

Final

14. Spunsoring Azency Code

15. SUPPI.EMENTARY NOTES

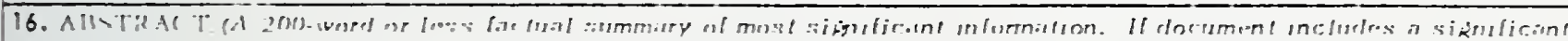

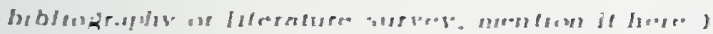

This report documents a data base "system" created at the National Bureau of Standards. The National Network Data Base System (NNDBS) provides information on Elows of freight and passengers throughout the transportation system of the United States. It consists of a set of FORTRAN-programs-written for -the-NBS -. UNIVAC 1108 (but transportable) and some basic data tapes. In addition to providing basic data on the transportation network, the NNDBS can produce modal splits, aggregations over certain "zones" in the U.S., and is capable of easy extension to other uses. This report is intended as a user's guide and includes discussions of the data tapes and each of the programs. Complete listings and tape formats are also included.

17. KEY G'ORDS (six to twelve entries; alphabetical order; capitalize only the first fetter of the first key word unless a proper neme: sepdrated by semicolons) Comodity Flows; Data Base; Ereight Mode Choice; Market Split; Modal Choice; Modal Freight; National Transport Analysis; Regional Transport Analysis; Transportation Network.
13. AVAILAZILITY

$$
\text { [x Unlimited }
$$

For Dificial Distriburion. Do Not Release to NTIS

E Otie: Frnm Sup. of Doc., U.S. Government Printing Office Heining:on, D.C. 20.10?. SD C.ae.No.CI3

D Orde: Fonm National Technical Informution Se:tice (NTIS) spoingúield, Virginia 22151

\begin{tabular}{|l|c|}
\hline $\begin{array}{l}\text { 19. SECLRITY CLASS } \\
\text { (THIS REPURT) }\end{array}$ & 21. NO. OF PAGF.S \\
UNCLASSIFIED & 60 \\
\hline $\begin{array}{l}\text { 20. SFCURITY CLASS } \\
\text { (THISPACIF) }\end{array}$ & 22. Price \\
UNCLASSIF!ED & \\
\hline
\end{tabular}


n. 

NBSIR 75-912

(This number has been canceled in order to allow the records of Office of Tech. Pubs. to be brought up to date. A new number will be assigned when the report has been approved by WERB) 


世M 
